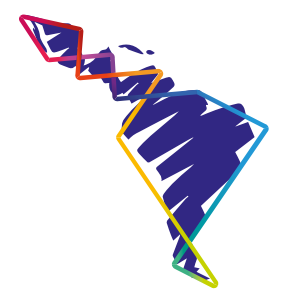

\title{
La violencia contra las mujeres trans en los espacios públicos: Entre el acoso sexual y la transfobia
}

\author{
Violence against trans women in public \\ spaces: Between sexual harassment and \\ transphobia
}

\section{Violência contra mulheres trans em espaços públicos: entre 0 assédio sexual e a transfobia.}

\author{
Karol Carmona Alvarado'
}

\begin{abstract}
Resumen
Este estudio tuvo como objetivo principal analizar, mediante el estudio de testimonios de mujeres trans, las manifestaciones del acoso sexual que enfrentan en los espacios públicos y que violentan sus derechos. Se realizó desde un paradigma de investigación cualitativa con algunos elementos de la investigación acción participativa, con un enfoque crítico de derechos humanos. Se trabajó con ocho mujeres trans, quienes brindaron sus testimonios mediante entrevistas a profundad semiestructuradas, las cuales se triangularon o compararon con periódicos, fuentes secundarias y se sistematizaron. Se complementó con una investigación de campo donde se estuvo contacto con el contexto y las personas en estudio. Entre los principales hallazgos: Los espacios públicos dominados por el hetero-patriarcado son, socialmente, destinados para el ejercicio de poder de los hombres contra las mujeres cisgénero y trans. La violencia que enfrenta la población trans desemboca en daños irreparables para sus vidas, compromete su integridad física y emocional y limita su acceso a los derechos humanos. El acoso sexual que viven las mujeres trans es acoso sexual transfóbico, porque se mezcla el acoso sexual con la transfobia. Lo anterior hace necesario que se realicen estudios desde diversas disciplinas que contribuyan a la visibilización histórica, social y política de estas poblaciones, además de contribuir desde
\end{abstract}

1 Costarricense. Posee una Maestría en Derechos Humanos y Educación para la Paz, licenciatura y bachiller en la Enseñanza de los Estudios Sociales y Educación Cívica. Es Bachiller en Historia y tiene un profesorado en Educación de I y II ciclo. Es docente universitaria y de secundaria. Actualmente trabaja para el Ministerio de Educación Pública de Costa Rica. Correo electrónico: karol.carmona.alvarado@mep.go.cr ORCID: https://orcid.org/0000-0002-7027-8871 
la academia a la construcción de un acervo documental que date las acciones, los logros, las vivencias y la historia de las poblaciones trans. Es importante realizar investigaciones desde enfoques cualitativos que acerquen y sensibilicen a quienes investigan con las realidades sociales, culturales y personales de las mujeres trans.

Palabras clave: Derechos humanos, acoso sexual, mujeres trans, transfobia, heteropatriarcado.

\begin{abstract}
The main objective of this study was to analyze, by studying the testimonies of trans women, the manifestations of sexual harassment that they face in public spaces and that violate their rights. It was carried out from a qualitative research paradigm with some elements of participatory action research, with a critical focus on human rights. Eight trans women subjects were investigated, who provided their testimonies through semi-structured in-depth interviews, which were triangulated or compared with newspaper reports, secondary sources, and systematized. The study was complemented with a field investigation whereby contact was had with the context and the people under study. Among the main findings: Public spaces dominated by heteropatriarchy are, socially, destined for the exercise of power by men against cisgender and trans women. The violence faced by the trans population leads to irreparable damage to their lives, compromises their physical and emotional integrity, and limits their access to human rights. The sexual harassment experienced by trans women is transphobic sexual harassment, because sexual harassment is mixed with transphobia. This makes it necessary to carry out studies from various disciplines that contribute to the historical, social and political visibility of these populations, in addition to contributing from academia to the construction of a documentary collection that dates the actions, achievements, experiences and the history of trans populations. It is important to carry out research from qualitative approaches that consolidate and sensitize those who investigate with the social, cultural and personal realities of trans women.
\end{abstract}

Keywords: Human rights; Sexual harassment; Trans women; Transphobia; Heteropatriarchy.

\title{
Resumo
}

O objetivo principal deste estudo foi analisar, por meio do estudo de depoimentos de mulheres trans, as manifestações de assédio sexual que enfrentam em espaços públicos e que violam seus direitos. Foi desenvolvida a partir de um paradigma de pesquisa qualitativa com alguns elementos da pesquisa-ação participativa, com enfoque crítico nos direitos humanos. Foram atendidas oito mulheres trans, que prestaram seus depoimentos por meio de entrevistas semiestruturadas em profundidade, que foram trianguladas ou comparadas com jornais, fontes secundárias e sistematizadas. Foi complementado com uma investigação de campo onde se fez contato com o contexto e as pessoas em estudo. Entre as principais constatações: Os espaços públicos dominados pelo heteropatriarcado são, socialmente, destinados ao exercício do poder por parte dos homens contra as mulheres cisgênero e trans. A violência enfrentada pela população trans acarreta danos irreparáveis à sua vida, compromete sua integridade física e emocional e limita seu acesso aos direitos humanos. O assédio sexual experimentado por mulheres trans é o assédio sexual transfóbico, porque o assédio sexual se mistura com a transfobia. Para isso, é necessária 
a realização de estudos em diversas disciplinas que contribuam para a visibilidade histórica, social e política dessas populações, além de contribuir desde a academia para a construção de um acervo documental que data as ações, conquistas, experiências e história das populações trans. É importante realizar pesquisas a partir de abordagens qualitativas que reúnam e sensibilizem aqueles que investigam com a realidade social, cultural e pessoal das mulheres trans.

Palavras-chave: Direitos humanos; Assédio sexual; Mulheres trans; Transfobia, Heteropatriarcado.

\section{Introducción}

Este artículo se desprende del capítulo III de una investigación llamada ¡Ni putas! ¡Ni travestis! La violencia contra las mujeres trans: Testimonios sobre el acoso sexual en los espacios públicos, la cual llenó un vacío detectado en los estudios elaborados desde las ciencias sociales y humanas en Costa Rica sobre poblaciones trans. Existían diversos trabajos con poblaciones sexualmente diversas, pero pocos con mujeres trans relacionados con el acoso sexual en el ámbito público con un enfoque cualitativo y testimonial, lo que hizo que el estudio fuera innovador y pionero en la temática. También fue transcendental porque fue un aporte al conocimiento, dado que la temática no había sido estudiada de manera profunda en la academia, tampoco había sido abordada en las instituciones públicas encargadas de trabajar en derechos humanos y en género ni en las organizaciones no gubernamentales ni, de forma general, por el Estado costarricense. Fue importante porque comprendió los contextos y las vivencias de las mujeres trans mediante un enfoque de derechos humanos.

La investigación contribuyó también a los estudios de derechos humanos, pues resultó valioso hacer un abordaje desde los enfoques críticos de derechos humanos como parte de una posición ético-política que pretendió reivindicar la dignidad humana, promover y visibilizar los procesos históricos de luchas y resistencias. Además, fue una propuesta epistemológica contra la hegemónica y de resistencia contra aquel pensamiento moderno que ha aniquilado los conocimientos, luchas y saberes de las comunidades sexualmente diversas (y otras) involucradas en los procesos de liberación.

El objetivo general que se planteó fue analizar, mediante el estudio de testimonios de mujeres trans, las manifestaciones de acoso sexual que ellas enfrentan en los espacios públicos y que violentan sus derechos. De este objetivo general se desprendieron cinco objetivos específicos: mostrar cómo la legislación costarricense ha abordado los derechos humanos de las poblaciones trans e identificar los procesos históricos emprendidos por las mujeres trans en Costa Rica; se explicaron los daños 
emocionales que se producen en las vidas de las mujeres trans que han vivido el acoso sexual en los espacios públicos y cómo estas se manifiestan en su vida; se identificaron las prácticas de resistencia articuladas por las mujeres trans ante el acoso en los espacios públicos. Se finalizó con la difusión por medio de mesas de diálogo dentro de instituciones públicas y privadas con experiencias e historias de vida sobre el acoso sexual en el ámbito público que enfrentan las mujeres trans.

Actualmente hay trabajos académicos muy recientes con mujeres y hombres trans en Costa Rica. Se han realizado investigaciones en el área de derechos humanos, específicamente sobre la vulnerabilidad y violación al derecho al trabajo formal de mujeres trans, se han presentado trabajos finales de graduación en la Enseñanza de los Estudios Sociales y Educación Cívica en torno a la participación ciudadana de esta comunidad sexualmente diversa. Desde las relaciones internacionales hay estudios sobre los derechos humanos, la calidad de vida de la población trans, además existen otras investigaciones relacionadas con los derechos humanos, salud y crímenes de odio, lo que evidencia que es un tema que está tomando auge en los estudios académicos.

\section{Antecedentes}

Los estudios que se analizaron en este apartado fueron antecedentes transcendentales para esta investigación, porque aportaron contextos socio-culturales e históricos tanto en Costa Rica como en Latinoamérica sobre mujeres trans. Facilitaron conocimientos y reflexiones teóricas y metodológicas que orientaron el estudio desde enfoques contra hegemónicos como son los enfoques críticos de derechos humanos, de género desde referentes metodológicos cualitativos. Las obras evidenciaron la necesidad de trabajar en temas sobre acoso sexual en los espacios públicos con poblaciones trans y desde enfoques críticos de derechos humanos, ya que son casi inexistentes

Berkins (2003), en el artículo: "Un itinerario político del trasvestismo"; este hace referencia a los procesos históricos de luchas emprendidos por las poblaciones trans en Argentina. Presenta un panorama sobre las luchas fragmentadas del movimiento LGTBI en la década de 1990 y las manifestaciones de discriminación que se generaron dentro del mismo movimiento de la diversidad sexual. El trabajo fue fundamental porque realiza un recuento histórico del movimiento trans, pero principalmente porque fue un estudio construido por una mujer trans que estuvo vinculada a las movilizaciones sociales por los derechos humanos de estas poblaciones. 
La investigación de la Red Lactrans (2015), llamada "Violaciones a los derechos humanos de mujeres trans en Costa Rica, El Salvador, Guatemala, Honduras y Panamá", facilita un análisis y una sistematización profunda de las situaciones de violencia y los procedimientos de denuncia que enfrentan las mujeres trans en Centroamérica y Panamá. Proporciona las bases de datos que visibilizan las diversas formas de discriminación y violencia sexual que enfrentan en toda la región centroamericana; datos que son transcendentales para construir los universos de estudio de esta investigación.

El artículo de Cordo y Corneli (2006), "El cuerpo travesti. Expresión de la lucha por la diversidad", plantea un análisis del cuerpo de las mujeres trans, las reivindicaciones y las luchas para validar sus identidades sexuales y de género. El análisis que realizan las autoras se cimienta en los estudios de subjetividades de las mujeres trans, lo cual es una fuente imprescindible para esta investigación, dado que se reconstruyeron contextos desde un enfoque testimonial y desde las percepciones de las mujeres trans.

Schifter (1998), en De ranas a princesas, sufridas, atrevidas y trasvestidas, entre los principales objetivos contiene analizar los riesgos de contagio de VIH en las mujeres trans que laboran en el comercio sexual en Costa Rica. Visibiliza las diversas culturas sexuales, los sueños y problemas que enfrentan las mujeres trans en Costa Rica. Este trabajo es uno de los primeros estudios que se realizaron con mujeres trans en el país.

Relacionados al acoso sexual, se incluyó: "El acoso sexual en lugares públicos: Un estudio desde la Grounded Theory", de Gaytán Sánchez (2007), un artículo sociológico que muestra un proceso de investigación y los resultados que se obtuvieron desde un enfoque empírico y cualitativo, realizado con las metodologías de la teoría fundamentada sobre el acoso sexual, en lugares públicos de la ciudad de México. Entre los principales objetivos del estudio estuvieron encontrar los diversos significados de cómo el acoso heterosexual por parte de los hombres hacia las mujeres permite la construcción de conceptualizaciones de acoso sexual, del acoso sexual en espacios públicos y del poder en el género, definiciones esenciales para este naciente trabajo.

La tesis de trabajo social El acoso callejero y sus implicaciones expresadas a través de la dominación masculina y la violencia simbólica en las mujeres del cantón de Grecia durante el año 2015, de Arias Cruz (2016) constituye uno de los pocos estudios académicos que hay en Costa Rica sobre el acoso sexual callejero que enfrentan las mujeres. Proporciona un marco teórico que sirve de guía para la elaboración de los referentes teóricos de esta investigación. La autora debate 
diversos conceptos como dominación masculina, patriarcado, piropo, la violencia simbólica y las representaciones hegemónicas del cuerpo femenino; lo que facilita un panorama teórico amplio para la comprensión integral del acoso sexual. De esta tesis se tomarán algunos conceptos para ser incluidos durante todo el trayecto de la investigación.

Del piropo al desencanto: Los significados de la interacción en el acoso sexual en lugares públicos, de Gaytán (2009), es un texto con enfoque sociológico que estudia el acoso sexual callejero como una forma de violencia invisible para las personas involucradas. La fuente mapea los lugares donde es predominante este tipo de manifestaciones de violencia como lo son las calles, los espacios de recreación, el transporte público, etc., lo que facilita demarcar, en esta investigación, los lugares donde las mujeres trans pueden sufrir acoso sexual.

Desde el área de los derechos humanos se incorporó el estudio de Gallardo (2007), "Fundamentos sobre los derechos humanos", donde se realiza una introducción a la discusión sobre los referentes conceptuales y los fundamentos de los derechos humanos, su eventual cumplimiento en lo jurídico y lo cultural principalmente en América Latina. El autor critica el enfoque colonizador del pensamiento moderno vigente en la conceptualización y la praxis de derechos humanos, presente en el ordenamiento jurídico internacional estandarizado y homogenizador, lo cual también se encontrará dentro de este proceso de investigación. Gallardo facilita la contextualización latinoamericana de los derechos humanos, lo que direcciona hacia la necesidad de construir investigaciones de derechos humanos desde las realidades del contexto de estudio y desde América Latina.

De Herrera Flores (2005) se revisó el libro La complejidad de los derechos humanos, bases teóricos para una definición crítica. Dentro de los aportes de la obra se encuentra la facilitación de un marco teórico referencial contra hegemónico, que cuestionan la racionalidad moderna, el universalismo y el garantismo impuesto sobre los derechos humanos. En las reflexiones del autor se pueden detectar las acciones de los Estados para anular los procesos históricos de lucha y cómo esto es un referente para comprender las acciones y omisiones históricas del Estado costarricense en materia de derechos humanos A pesar de las críticas del autor al ordenamiento jurídico internacional, él percibe la necesidad de que haya una base mínima de legislación que les permita, a las poblaciones vulnerables, desde lo legal, exigir los bienes materiales para vivir. Asimismo, propone que los derechos humanos no deben limitarse a la teoría, sino que estos deben transcender a la praxis sociopolítica e histórica. 


\section{Referentes teóricos}

Para la investigación se consideraron componentes teóricos que permitieron, de forma ordenada, dar la orientación adecuada a las perspectivas epistemológicas. En primera instancia se mencionan algunos conceptos relativos a los derechos humanos.

\section{Derechos humanos}

Los distintos conceptos de derechos humanos han ocupado un eje central en los debates epistemológicos actuales y han variado a través de las diversas coyunturas históricas. Según Gutiérrez-García (2013), los enfoques hegemónicos modernos positivistas los han posicionado como un conjunto de normas e instituciones de carácter legal y judicial llamado ordenamiento jurídico de los derechos humanos. Desde esta perspectiva se edificó un esqueleto jurídico internacional basado en normas supuestamente "universales" que son aplicadas en diversos contextos socio-culturales y validados por medio de la institucionalidad estatal e internacional. Los derechos humanos modernos son representaciones burguesas, Gallardo-Martínez (2007), define esta posición tradicional como:

Derechos humanos debe ser considerado un nombre propio para capacidades jurídicas específicas que pueden ser reclamadas en circuitos judiciales. En cuanto capacidades jurídicas remiten a relacionalidades sociales. Su nombre propio deriva, en apariencia, del ideologema liberal del principio (universal) de agencia humana (Gallardo, 2007, p. 14).

Este posicionamiento tradicional los limitó a dispositivos regulatorios explicados y aplicados únicamente desde lo técnico y lo legal propuesto en los textos jurídicos positivistas. Los concibe de manera reduccionista y excluyente, entendidos y ejecutados desde la cosmovisión occidental, capitalista y patriarcal. Este enfoque se caracteriza por la reproducción de lineamientos epistemológicos e ideológicos dominantes con determinada intencionalidad política y discursos análogos de los relatos "únicos y verdaderos" (Gutiérrez- García, 2013).

Desde estas visiones epistemológicas modernas de los derechos humanos, los distintos pueblos, los sectores sociales excluidos y las minorías se han visto condicionados a las normas legales y las regulaciones jurídicas - institucionales de los intereses del sistema moderno-capitalista-liberal. Después de la Segunda Guerra Mundial los marcos jurídicos internacionales se han usado para consolidar el expansionismo económico y militar de las grandes potencias mundiales sobre el resto de países pobres mediante inversiones ideológicas. 
Ante las limitaciones de los enfoques hegemónicos de los derechos humanos, fue necesaria la construcción de nuevos modelos teóricos-prácticos que brindaron aportes epistemológicos sobre los procesos de luchas y transformaciones de los colectivos silenciados y olvidados. Es transcendental posicionarse desde percepciones emancipadoras y decoloniales de los derechos humanos. Gutiérrez-García (2013) establece que estos pueden definirse como espacios de inclusión, de construcción social e institucional direccionados a las luchas contrahegemónicas del sistema capitalista- imperialista y patriarcal.

Los postulados críticos de los derechos humanos se entienden desde el pensamiento no occidentalizado, y construyen posiciones emancipadoras contextualizadas a las diversas realidades de los grupos excluidos. Según Gutiérrez-García (2013), esta teoría se muestra sensible a las diversas inquietudes y necesidades de los sectores excluidos hostilizados, ignorados u olvidados por las diversas expresiones hegemónicas. Para Herrera-Flores (2005), esta es una posición epistemológica que las verdades ponen en las prácticas sociales que intentan día tras día conseguir el acceso de todas y todos a los bienes materiales e inmateriales que se han ido conquistando en el proceso de humanización.

Desde un enfoque crítico, los derechos humanos son consecuencias de los procesos históricos de luchas por la dignidad humana en la conquista del acceso a los bienes materiales de forma justa e igualitaria para todas las personas. La dignidad es un fin material, un objetivo que se concreta en dicho acceso igualitario y generalizado a los bienes que hacen que la vida sea "digna" de ser vivida (Herrera-Flores 2005).

Para Herrera-Flores (2005) también son importantes las luchas jurídicas por los derechos humanos por parte de los sectores sociales excluidos, porque las luchas desde lo jurídico abren espacios de empoderamiento e implementación de derechos dentro de los Estados, como ha sido la construcción de políticas públicas exigidas desde las bases populares.Herrera -Flores (2000); amplía lo anterior y considera que los derechos humanos son espacios de luchas donde se confrontan intereses por el poder, con el objetivo de conseguir universalizar sus posiciones para lograr fines determinados. Mediante las luchas emancipatorias, la lógica dominante acepta las propuestas básicas que se cimientan desde las bases que las exigen. Los derechos humanos, desde el punto de vista crítico, son una propuesta epistemológica-política emancipadora que se reconocen como un producto histórico de las luchas de las comunidades en busca de su liberación.

En relación con lo anterior, los sectores sociales sexualmente discriminados han abierto luchas históricas desde posiciones prácticas y teóricas, al enfrentarse a distintos 
obstáculos para garantizar su dignidad y libertad entre otros derechos. Ante ello fue transcendental exaltar la relación de los derechos humanos y el transfeminismo.

\section{Transfeminismo}

El transfeminismo ha sido una posición epistemológica-política que resultó de los procesos históricos de luchas por la dignidad y la justicia de algunas mujeres étnicamente distintas y de las comunidades sexualmente diversas como son las mujeres trans. Valencia-Triana (2014, p. 67) lo define así:

Articulación tanto del pensamiento como de resistencia social que es capaz de integrar la movilidad entre géneros, corporalidades y sexualidades con los supuestos de las luchas feministas, a fin de construir alianzas con las masculinidades no hegemónicas, para crear una organización reticular irreductible a la oposición entre géneros.

El transfeminismo, para Valencia-Triana (2014), es una propuesta epistemológica-contra-hegemónica vinculada con los postulados feministas. Es una red que abre espacios para las minorías y algunas mujeres que han sido excluidas por el feminismo dominante blanco e institucionalizado. Por su parte, Curiel-Pichardo (2014) expresa que el feminismo tradicional es colonialista, clasista y reproduce las mismas desigualdades raciales, étnicas de las teorías modernas, invisibilizando las distintas realidades socio-históricas y culturales.

Para Valencia-Triana (2014), el trasfeminismo construye vínculos con la memoria histórica; reconoce las luchas heredadas por los diversos movimientos de la liberación de las mujeres, los cuales fueron compuestos y apoyados por otros sectores históricos excluidos como las minorías étnicas, raciales, migrantes y personas en condición de pobreza. Es una propuesta que se ha edificado desde la dialogía y el accionar político y discursivo en relación con estos grupos sociales. Según Cabrera y Vargas (2014), el transfeminismo realiza críticas al feminismo hegemónico heterocolonial, reconceptualiza la raza-sexo-género y la sexualidad, deconstruye las identidades, edifica post identidades y reorienta las políticas relativas a la corporalidad.

De acuerdo con lo manifestado por Valencia-Triana (2014), el transfeminismo visibiliza y empodera a los múltiples colectivos que constituyen las mujeres, entre ellas a las mujeres trans (no exceptúa). Esta teoría propone la construcción de políticas disidentes que visibilicen los movimientos sexualmente diversos, incluye y se posiciona políticamente desde sus postulados a favor de otros sectores sociales que han estado en desventaja. Para el transfeminismo, esas formas de discriminación 
y fobias se sostienen por el patriarcado y el autoritarismo promovido desde el sistema capitalista.

\section{Transfobia}

Para Ulises-Borgogno (2009), una de las expresiones de la homofobia se denomina transfobia. La transfobia es la discriminación que se ejerce contra las poblaciones trans, es la no aceptación, el miedo o el desprecio hacia quienes tienen identidades de género y expresión de género trans. Es el rechazo y discriminación hacia las personas que sienten que su identidad de género no coincide con el sexo que poseen.

La transfobia, como lo establece Ulises-Borgogno (2009), se manifiesta en diversos contextos de la vida de los seres humanos trans: en la institucionalidad pública como la escuela y la salud, en la familia, en el ámbito laboral, así como en el sistema jurídico legal y en las actividades que se realizan cotidianamente en el espacio público. La transfobia niega las expresiones e identidades de género que se eligen, con lo cual atenta contra la autonomía, la dignidad y la vida de las personas trans. Las expresiones transfóbicas obstruyen y anulan otros derechos humanos como el acceso a la salud, al trabajo y a la educación, así como la identidad, la familia, la vida y la libertad, entre otros.

La transfobia se expresa constantemente en el espacio público. El espacio público es un territorio visible donde se supone que cualquier persona puede estar y trasladarse libremente. Debe caracterizarse por ser accesible para toda la ciudadanía, donde se generen diálogos cotidianos entre las personas y la institucionalidad. No obstante, en estos sitios se articulan relaciones de poder que forjan inequidades sociales económicas, culturales y de género. El espacio público, para Borja-Jordi (2003), se encuentra delimitado y se convierte en un lugar donde se ejerce el poder por parte de grupos sociales y políticos hacia otros regularmente excluidos. Los grupos sociales que hacen uso del poder restringen el uso al territorio y con ello la libertad de desplazamiento de otras poblaciones. El sistema patriarcal tiene limitado el espacio público para las mujeres, este se convierte en un lugar donde se ejerce y se expresa el poder de los hombres; las mujeres son violentadas constantemente de diversas maneras en el espacio público, lo cual es normalizado y naturalizado por el patriarcado.

\section{El patriarcado}

El patriarcado es el ejercicio del poder de los hombres hacia las mujeres. Es una forma de organización política, económica, religiosa y social cimentada en la autoridad de lo masculino. En este sistema los hombres administran y se apropian de 
las sexualidades e identidades de las mujeres. Se sustenta en un orden simbólico que se justifica por medio de mitificaciones amparadas en su gran mayoría por las religiones y los Estados, los cuales reproducen el patriarcado como la única estructura posible (Reguant, 2014).

El sistema patriarcal construye relaciones de inferioridad basadas en enfoques biológicos que son asumidos como naturales, se sustenta en las diferencias entre hombres y mujeres, posiciona a las últimas en desventaja y desigualdad. Es el dominio de lo masculino que se reproduce en el núcleo familiar sobre las mujeres y las niñas y los niños, y se expande a toda la sociedad. Son los hombres quienes controlan la institucionalidad y despojan a las mujeres del acceso a estas. De acuerdo con Facio-Montejo (2000), el orden patriarcal es una postura asentada en el principio absoluto de lo masculino. Miller (2004), expresa:

El capitalismo y el patriarcado siempre han estado vinculados. El capitalismo necesita hombres y mujeres en familias lo suficientemente extensas al menos para reproducir la próxima generación de trabajadores. La primacía ideológica de la familia garantiza que una sociedad capitalista reproducirá no sólo niños, sino también la heterosexualidad y la homofobia (y transfobia) (Miller 2004, p. 13).

El patriarcado, expresado en el espacio público, ha generado la violencia de género contra las mujeres y comunidades LGTBI. La violencia de género se ejerce a través de posiciones de poder de dominación-sumisión, alguien que se supone posee el poder somete a la fuerza a quien considera con mayor debilidad. Cuando se hace referencia a la violencia de género contra las mujeres en relación con los hombres se origina y se manifiestan problemas de desigualdad y de sometimiento de estas. Según Rico (1996), la violencia de género es:

Toda conducta que atenta contra la dignidad e integridad física y moral de las mujeres por el hecho de serlo, como manifestación de la discriminación, la situación de desigualdad y las relaciones de poder de los hombres sobre las mujeres". "La violencia comprende cualquier acto de violencia basada en género que tenga como consecuencia, o que tenga posibilidades de tener como consecuencia, perjuicio o sufrimiento en la salud física, sexual o psicológica de la mujer, incluyendo amenazas de dichos actos, coerción o privaciones arbitrarias de su libertad, tanto si se producen en la vida pública como privada, (Rico 1996, p. 31)

Para Rico (1996), la violencia de género es una forma de ejercicio del poder que atenta contra una gama de derechos como lo es la vida, la libertad, la seguridad y la dignidad de las mujeres. El acoso sexual en los espacios públicos es una manifestación de la violencia de género y puede conceptualizarse como una agresión sexual 
invisible, socialmente aceptada. Para Arias-Cruz (2016), son las acciones que se producen cotidianamente y de manera normalizada donde de manera individual o colectiva, individuos desconocidos abordan a una o varias personas en el espacio público para ejecutar acciones violentas como gestos, acercamientos o comentario denigrantes, irrespetuosos que atentan contra la dignidad y la vida humana.

\section{El acoso sexual en los espacios públicos}

Según Guillén-Flores (2014), el acoso sexual es cualquier expresión verbal y física violenta indeseada con el objetivo de denigrar e inferiorizar a las personas en los lugares públicos. Sus manifestaciones son diversas, incluyen desde la violación del derecho a la imagen por medio de grabaciones o fotografías sin consentimiento, persecución y exhibicionismo, "toqueteos" y acercamiento de los genitales sobre el cuerpo de la víctima para afianzar el poder del victimario. Para la autora, este tipo de violencia coloca a los seres humanos como objetos sexuales públicos y los cosifica; y el espacio público adquiere una dimensión sexual donde se ejerce el poder por la parte de sujetos acosadores sobre las víctimas, las que, principalmente, suelen ser mujeres. Quien hostiga se siente con el derecho otorgado por el falogocentrismo de interceptar a las personas en lugares públicos, manifestar comentarios y acciones sin consentimiento.

Para Retana (2016), el acoso sexual en los lugares públicos es una agresión individual dentro de un contexto sociocultural colectivo demarcado por la lógica patriarcal. Esta forma de violencia naturalizada y legitimada en beneficio de los hombres, quienes por medio del poder otorgado controlan y valoran subjetivamente el cuerpo de las mujeres, también tienen el poder para arremeter contra la corporalidad no binaria. El acoso sexual es una forma de violencia de género que evidencia el desbalance de los géneros en los espacios públicos, otorgando privilegios y flexibilidades principalmente a los varones que cumplen con la masculinidad hegemónica.

El acoso sexual en los espacios públicos genera una gama de emociones y percepciones sobre la seguridad y la autoestima de quien lo enfrenta a diario; las personas sexualmente diversas y con identidades de género no establecidas tienden a ser víctimas constantes de este flagelo. En el caso específico de las mujeres trans, ellas están obligadas a vivir dentro del capitalismo patriarcal bajo construcciones sociales, roles e identidades de género establecidas e inquebrantables, impuestas desde la lógica binaria: pene/vagina, hombre/mujer, masculinidad/feminidad. Al romper con dichas normas hegemónicas se convierten en una población extremadamente vulnerable de padecer la violencia de género expresa mediante el acoso sexual. 


\section{La educación crítica}

La educación crítica es una práctica que promueve la resistencia y la reflexión, deconstruye los discursos que cimientan los privilegios y el poder; empodera y promueve la movilización social. Permite adquirir conocimientos por medio de la comunicación dialógica y la práctica reflexiva a aquellos sujetos sociales que se les ha negado la palabra. Por la naturaleza de este trabajo fue transcendental incluir en este apartado algunos referentes teóricos de la pedagogía crítica, entendida esta como una práctica liberadora. Para Magendzo-Kolstrein (1999), existen vínculos claros entre la pedagogía crítica y las luchas por los derechos humanos, dado que este enfoque teórico-metodológico observa y trabaja desde lo teórico y lo práctico contra las estructuras del poder como una forma de resistencia.

Igualmente, la pedagogía crítica se interesa por desarticular las imposiciones verticales, relaciones autoritarias y rígidas impuestas contra una gran cantidad de seres humanos, mientras el aprendizaje (no precisamente formal) se desarrolla en un ambiente de diálogo y comunicación. La pedagogía crítica propone que las personas oprimidas se transformen en personas autónomas, independientes del poder para que sean ellas mismas quienes se empoderen de sus propios conocimientos, desarrollen historias de vida y mantengan viva la memoria histórica. Según Mirabal-Paterson (2008), puede definirse como una propuesta teórico-metodológica de la pedagogía basada en el saber popular. Se direcciona la construcción colectiva del conocimiento por medio del diálogo: la comunicación dialógica, parte de la praxis y de las historias de vida de los grupos oprimidos para concretizar el proceso de acción-reflexión-acción.

Este enfoque pedagógico, según la autora, promueve el respeto a las diversas identidades y a lo diferente: no subestima el conocimiento de los sujetos sociales oprimidos, reconoce los universos y los mundos de los seres humanos, crea relaciones horizontales, potencia el amor, la reflexividad y la fe, generando agentes activos en los procesos de transformación social. El método de la educación crítica en derechos humanos respeta los saberes de las personas, más aún aquellos saberes construidos desde los grupos oprimidos por el poder. Transforma, por medio del diálogo, las imposiciones epistemológicas que se justifican desde los sistemas injustos y desiguales, como el capitalismo y el patriarcado. Según Duhalde (2008), se inicia desde la curiosidad crítica, partiendo del sujeto oprimido, pero no para quedarse, sino justamente para partir a otro lugar, es decir, hacia la liberación.

Estos referentes teóricos fueron indispensables para elaborar la investigación, dado que proporcionaron las bases teóricas y los debates epistemológicos que sustentaron el tema y permitieron desarrollar los objetivos planteados. Ante lo 
anterior, fue necesario que estas teorías y conceptos no solo sirvieran como sustento teórico al proyecto; estos referentes epistemológicos fueron también aplicados en la sistematización de los datos, las conclusiones y en la propuesta metodología en todos los capítulos de la investigación. El debate teórico que se propuso sirvió para contextualizar al público lector y a la investigadora en el tema y las problemáticas del estudio.

\section{Propuesta metodológica}

Este estudio fue cualitativo e interdisciplinario porque involucró componentes teóricos de los enfoques críticos de derechos humanos, la pedagogía crítica y la ecología de saberes. Se usaron propuestas teóricas críticas de los derechos humanos para entender las luchas trans como movimientos históricos de lucha, para que estos no sean vistos desde lógicas reduccionistas positivistas que se limiten a entender los derechos humanos solo desde el ordenamiento jurídico moderno y racionalista.

Se utilizaron algunos postulados teóricos y metodológicos de la pedagogía crítica que tiene que ver con las prácticas de la educación crítica y liberadora. Este enfoque educativo es usado para trabajar con grupos históricamente excluidos; propone la comunicación dialógica como punto de encuentro entre las personas involucradas en los procesos de investigación.

Por la naturaleza de este estudio, además de ser una investigación cualitativa, tiene algunas características de la investigación acción participativa (IAP) porque no solo presenta resultados académicos y contribuye al conocimiento, sino que también intenta lograr cambios paulatinos en la vida social y personal de las mujeres trans, por ejemplo, mejorar su autoestima, abrir espacios para que sus problemáticas se hagan visibles y sean escuchadas, entre otros.

\section{Población y muestra y formas de acercarse a las actrices de la investigación}

Para la ejecución del estudio se trabajó con ocho mujeres trans que vivían en el Valle Central. Las edades de estas mujeres oscilan entre los 20 y los 60 años, sus condiciones socioeconómicas son diversas, sus trabajos son distintos y sus relaciones comunales y familiares diferentes; todo esto facilitó realizar varias interpretaciones y cuestionamientos en la sistematización de este estudio. Las mujeres con quienes se trabajó son parte de una población difícil de acercarse en comparación con otros colectivos sociales; porque no son numerosas y por la resistencia que generan ante la violencia y la estigmatización social que enfrentan diariamente; ante ello se tuvo que hacer contacto con una mujer trans para ir contactado algunas

$14 \begin{aligned} & \text { Revista Latinoamericana de Derechos Humanos } \\ & \text { Volumen } 32 \text { (1), I Semestre 2021 } \\ & \text { ISSN: 1659-4304 • EISSN: 2215-4221 }\end{aligned}$ 
otras; también, mediante feministas intersectoriales, que facilitaron vínculos con otras mujeres trans.

\section{Rutas de vida}

La ruta de vida permitió ampliar y explicar, de forma completa e integral, las características individuales de las mujeres trans con las que se trabajó, para comprender los universos sociales culturales y económicos en estudio. Se hizo necesario recolectar algunos elementos de las historias personales, narrativas y descripciones de las experiencias de las mujeres trans para ofrecer un panorama más amplio del contexto en estudio. Estas experiencias y perspectivas subjetivas se analizaron de manera individual para entender un poco las vidas de cada una de las informantes, pero también como parte de las vidas colectivas de las personas trans. Esto se incluyó en el capítulo III de la investigación.

\section{Técnicas e instrumentos de recopilación de información}

Se usaron las siguientes técnicas de investigación, porque fueron las que mejor se adaptaron a los propósitos que perseguía este trabajo: la investigación de campo, rutas de vida, diario de investigación y entrevistas a profundidad semiestructuradas.

La investigación de campo. Esta se caracterizó porque la investigadora estuvo en contacto directo con el contexto y con las mujeres trans del estudio, con el fin de recopilar los datos y la información necesaria. Se analizaron y entendieron los contextos sociales-culturales donde se desenvuelven estas, con el objetivo de encontrar respuestas, conclusiones, soluciones a las problemáticas del acoso sexual en los espacios públicos vividos desde las realidades de ellas mismas. Se interpretaron los contextos de forma más subjetiva y vivencial.

\section{Entrevistas a profundidad semiestructuradas}

El trabajo recopiló testimonios sobre el acoso sexual que enfrentan las mujeres trans en los espacios públicos (este es el tema principal del estudio). Para obtener los testimonios se recurrió a las entrevistas, las cuales facilitaron el acercamiento a las personas participantes en la investigación, los acontecimientos que viven y las valoraciones que hacen respecto a este tipo de violencia. A través de las entrevistas ellas pudieron narrar lo vivido, pero no se limitó a la esencia de los testimonios, sino que se vincularon con las diversas realidades, contextos o situaciones para entender, de forma integral, el fenómeno. 
Mediante esta técnica de recolección de información las informantes dieron elementos cognoscitivos, ya sean experiencias, vivencias, cotidianidades, sus posiciones y orientaciones, expectativas, deseos y motivaciones sobre las temáticas que la investigadora les propuso. Por medio de la comunicación dialógica propuesta pedagogía crítica se aprendió, de forma colectiva, se generaron reflexiones profundas sobre problemas como es el caso del acoso sexual en los espacios públicos en la vida de las mujeres. Se construyó el conocimiento de forma social, edificando lazos entre las participantes, se abrieron procesos de deseducación y reaprendizaje que permiten desarrollar la criticidad.

\section{El método comparativo y la triangulación}

Se utilizaron el método comparativo y la triangulación de fuentes escritas como periódicos y libros con los testimonios orales sobre el acoso sexual en los espacios públicos.

\section{Diario de investigación}

Se usó un diario de investigación que facilitó recopilar la información que se observó, que se escuchó durante todo el proceso de investigación que tuvo relación con los objetivos del estudio. Esta técnica consiste en construir notas acumulativas o narraciones sobre determinadas personas y sus contextos sociales. Son narraciones periódicas de incidentes de las conductas y anécdotas de las personas; los datos se estructuran de modo que facilita la comprensión de los contextos y las conductas de forma global de los seres humanos con que se trabaja, en este caso las mujeres trans.

\section{Sistematización de la información}

Se procedió a sistematizar la información a través del análisis de datos, la triangulación y el método comparativo. Los datos recopilados por medio de las entrevistas y el diario de investigación se contrastaron con las teorías del marco referencial, las perspectivas de derechos humanos y la información publicada en los medios de comunicación y otras fuentes que abordan la temática del acoso sexual en los espacios públicos. Se realizó un cuadro con diversos aspectos cualitativos desprendidos de los objetivos de investigación sobre el acoso sexual en los espacios públicos que viven las mujeres trans Los aspectos fueron: manifestaciones de acoso sexual en el espacio público. Manifestaciones de acoso sexual en la institucionalidad pública, daños en la vida de las mujeres resistencias, los cuales se desarrollaron en los capítulos III y IV. Posteriormente se analizaron estos datos para realizar las reflexiones necesarias y se confrontaron con los objetivos planteados, para ver si 
se cumplió con los fines establecidos al inicio de esta investigación y durante todo el desarrollo metodológico.

\section{Estrategia de difusión}

\section{Charlas}

Para concluir la investigación se organizaron cuatro charlas de difusión donde las mujeres trans socialicen sus historias de vida sobre el acoso sexual en espacios públicos que enfrentan cotidianamente las mujeres trans. Estas ser realizaron en la UNA y en una universidad privada. El objetivo fue abrir espacios de diálogo y de lucha contra la violencia de género que enfrenta el grupo en estudio. Se intentó posicionar a las mujeres trans como protagonistas principales de sus propias historias, es decir, devolverles la palabra como lo establece la pedagogía de la liberación, abrir el campus para escuchar las poblaciones excluidas y, con ello, romper con la verticalidad de conocimiento hegemónico impuesto por la intelectualidad académica.

Estas charlas promovieron la ecología de saberes, como una propuesta metodológica de investigación y extensión que potencia la interactividad ante la unilateralidad del conocimiento. Para De Sousa-Santos (2010), es una invitación al intercambio de conocimiento científico surgido en la academia y los saberes populares-sociales, en este caso de las mujeres trans. Esta metodología procura que las universidades rompan con el pensamiento hegemónico científico "verdadero" que sigue siendo reproducido por los ámbitos intelectuales en estas instituciones. Con este proyecto se pretendió que las universidades públicas y otros lugares sean espacios de reflexión e intercambio de conocimientos entre las diversas poblaciones o comunidades que viven y enfrentan las problemáticas sociales y quienes integran de la academia.

\section{Reflexionando sobre el acoso sexual en los espacios públicos contra las mujeres trans}

El acoso sexual hacia las mujeres trans es un tipo de violencia falogocentrista y transfóbica que enfrentan diariamente ellas en la mayoría de los lugares públicos del país. El acoso sexual es una forma de violencia que ha sido naturalizada en Costa Rica, su existencia es cotidiana en los espacios públicos, los cuales son espacios dominados por las violencias patriarcales. Tanto los hombres como las mujeres la practican contra los cuerpos no binarios, no lo hacen solamente en la calle, sino en los diversos ámbitos de sus vidas privadas. Los lugares públicos/ privados son subyugados al hetero-patriarcado con una gran dosis de influencia religiosa cristiana (antropocéntrica, misógina y sectaria) donde se marcan y se 
reproducen las desigualdades, la discriminación hacia las diversas identidades de géneros y las distintas orientaciones sexuales.

Para Retana (2016):

El acoso sexual es la producción diferencial y performativa de los géneros, produce de forma inestable pero efectiva, cuerpos femeninos sometidos al escrutinio, la amenaza y la violencia, combatir el acoso sexual callejero y en los espacios públicos conlleva a desestabilizar las esencias de género y postular como posibles formas de habitar la categoría "mujeres". (pp. 50-53)

Para este autor, el acoso sexual en los espacios públicos marca la agresión individual en un contexto socio-histórico con lógica patriarcal- heteronormalizado, en el que se legitima socialmente a los hombres (diversos sin importar su raza, etnia o condición social) para que se pronuncien y se adueñen, sin permiso, sobre los cuerpos de las diversas mujeres (cisgéneros, transgéneros transexuales, indígenas, afrodescendientes, etcétera), es la cosificación del "no macho" en su máxima expresión; otorga a los hombres la libertad de evaluar cuando quieran los cuerpos feminizados.

Existe una violencia general que excluye a las personas por su origen nacional, grupo étnico, raza, etcétera, pero cuando esta violencia es patriarcal, el inmigrante que es excluido por la sociedad donde vive, asume su rol de hombre y se siente legitimado en el espacio patriarcal para ejercer la violencia sobre cualquier mujer o sobre todo lo que no se considere "macho".

Según Retana, actualmente denunciar el acoso sexual sufrido en el ámbito público visibiliza y reafirma la dimensión pública de la vida de las mujeres. Esta forma de violencia patriarcal ha sido históricamente invisible, en la actualidad visibilizarla y denunciarla conlleva a la feminización del espacio contra el hetero-patriarcado que se ejerce en estos lugares. Feminizar el espacio público habilita socialmente a pensar la violencia de género en la calle como parte de un entramado más amplio, uno que abarca la casa, pero también otras áreas de la vida de las mujeres (Retana, 2016).

En las sociedades occidentales, el acoso sexual en el ámbito público es una forma de agresión, la cual es soportada por aquellos cuerpos definidos como femeninos; es desde esta lógica que tanto mujeres cisgénero como trans son las principales víctimas de este tipo de discriminación. Para Retana (2016), las relaciones de poder generalizadas, basadas en el binarismo, separan los cuerpos masculinos de los femeninos, al sostener perjuicios y estigmas morales desde el falogocentrismo. 
Este último no solo interpone conceptos de género obligatorios sobre los hombres y mujeres e impone regulaciones en la vida de hombres y mujeres; pero, además, regula con una lógica, el carácter y los alcances desventajosos para estas últimas.

Este falogocentrismo encuentra en la sexualidad uno de los espacios y recursos para cimentar las desigualdades y consolidar privilegios. La sexualidad no solo ofrece un fundamento para la organización socio-simbólico del mundo cotidiano en términos binarios macho/hembra, sino que establece una serie de conductas propias e impropias para cada uno de los polos de esa oposición binaria (Retana, 2016).

El falogocentrismo constituye un sistema dual fundamentado en lo biológico. Dentro de la lógica binaria, la complementariedad obligatoria de los sexos fundamenta la heterosexualidad. Según Arias-Cruz (2016), al nacer como hombres o como mujeres se atribuyen obligatoriamente las construcciones sociales de lo masculino y lo femenino: actitudes, formas de actuar, percepciones cotidianas, entre otras.

Es desde la lógica falogocentrisma-heteronormativa que se justifica el acoso sexual que viven las mujeres trans en los espacios públicos. A partir de los datos descubiertos y los referentes teóricos transfeministas, se encontró que la identidad de género de las mujeres trans no solo quebrantan la binaridad biológica y cultural macho/hembra impuesta por el patriarcado, sino que rompe con la heterosexualidad normalizada, para proponer un nuevo concepto de heterosexualidad (en la cual mujer trans con un hombre cisgénero es considerada una pareja heterosexual), visibiliza las diversas orientaciones sexuales y quebranta la complementariedad obligatoria biológica de los sexos, pene/vagina, impuesta por el androcentrismo.

$\mathrm{Al}$ iniciar el proceso de transición, las mujeres trans feminizan sus cuerpos. Estos cuerpos, una vez feminizados según la lógica del patriarcado, pueden ser violentados, convirtiéndolas en personas muy vulnerables de sufrir acoso sexual, continuamente, en los espacios públicos. Cuando nacieron estas mujeres trans fueron clasificadas biológicamente como hombres, el hecho de renunciar al "privilegio" de ser hombres y transicionar ${ }^{2}$ a mujeres las pone en una posición de desventaja social, ya que son discriminadas por ser mujeres, pero también por renunciar a la masculinidad otorgada al nacer y al ejercicio de estar dentro del falogocentrismo.

Para la informante \# 1 Stacy, ellas bajan en la escala social al renunciar a ser hombres y por eso son vistas como menos por la sociedad (ver Anexo 1). Lo anterior se complementa con lo que expresó la informante \# 2 Victoria en la entrevista:

2 Verbo que utilizan las mujeres trans para referirse al proceso de cambio del género. 
No es una cuestión de que las violenten por ser mujeres trans, porque a las mujeres nos violentan a todas por igual, cuando una es percibida como mujer a una la violentan, cuando una es violada, abusada, cuando una es agredida etcétera, etcétera, a una la siguen violentando como mujer; el problema con las chicas trans es que cuando llegamos a poner esa resistencia, a decir $¡ H$ Hey, quiero poner una denuncia, si no me trata de esta manera o tal cosa! Entonces ahí se agrega otra violencia, porque te empiezan a violentar como hombre, (V. Rovira, comunicación personal, 4 de julio del 2017).

El proceso de feminización de los cuerpos trans y la renuncia de los "privilegios" masculinos que les impusieron al nacer a estas mujeres las ponen en mayor riesgo en el espacio dominado por la violencia patriarcal. Para las mujeres trans el acoso sexual que enfrentan ellas es el mismo acoso sexual que viven las mujeres cisgénero por ser mujeres. Es probable que no sea el mismo tipo de acoso; la intencionalidad y el carácter simbólico del acoso contra una mujer trans recalca la renuncia a lo masculino, es un hombre minimizado a lo femenino, un "maricón" por elección propia; en cambio, la mujer cisgénero es inferior sin elección. Las connotaciones del acoso pueden ser distintas, aunque las manifestaciones sean muy semejantes.

La informante \# 3 Samantha, compartió que al transicionar y renunciar al beneficio masculino otorgado al nacer, las mujeres trans comienzan a sufrir y entender el acoso sexual que viven las mujeres cisgénero todos los días:

Yo nunca he recibido como un ataque, pero sí he recibido el acoso que ustedes han estado acostumbradas toda la vida; fue literalmente como darme cuenta de lo que se llama perder todo el beneficio masculino. $\mathrm{O}$ sea, como que es demasiado violento (S. Salas, comunicación personal, 26 de junio del 2017).

Sin embargo, según las mujeres trans a pesar de que ellas definen que enfrentan el mismo acoso sexual que las mujeres cisgénero, consideran que en muchas ocasiones son doblemente violentadas por renunciar a la masculinidad dominante y por ser consideradas por la sociedad y las instituciones como hombres homosexuales.

La informante \# 4 Natalia dijo también que ellas son imaginadas y tratadas como objetos sexuales, las mujeres trans son percibidas socialmente por los estereotipos que existen, como sujetas abiertas a lo sexual y al libertinaje (N. Porras, comunicación personal, 3 de abril del 2017). En la entrevista Samantha expresó que una gran parte de la población costarricense las trata "como un fetiche, un pedazo de carne, una fantasía, un "nunca lo he hecho", un "con esto me masturbo", básicamente, como que nos quitan la parte humana y nosotras somos como muñecas inflables con pene" (Salas 2017). 
Como puede verse, estas mujeres enfrentan distintas formas y escalas de violencia: por ser mujeres, por ser hombres, por ser consideradas homosexuales y por ser vistas como objetos sexuales que cumplen las fantasías sexuales creadas por el mismo patriarcado. La cosificación de las mujeres en el sistema capitalista contemporáneo posiciona a estas como mercancía, como un bien material de alto consumo y de disfrute masculino.

La cosificación que enfrentan las mujeres trans es una cosificación de carácter sexual que representa y trata a estas poblaciones como objetos sexuales. Por medio de esta cosificación el capitalismo y el patriarcado, en una alianza inquebrantable, se rehúsan a validar las cualidades intelectuales, $\mathrm{y}$ las habilidades sociales y personales que estas mujeres tienen, deshumanizándolas y reduciéndolas a instrumentos de deleite sexual principalmente masculino.

En otro sentido, el acoso sexual que sufren las mujeres trans es una manifestación más de transfobia, lo cual conlleva daños físicos y psicológicos irreparables para estas personas. El acoso sexual transfóbico es una forma de violencia y discriminación patriarcal que sucede en los espacios públicos como calles, instituciones, lugares socio-recreativos, bares, supermercados y comercios, donde se ataca y se desprecia a las mujeres trans por su identidad de género.

También existen otros espacios o lugares de "buen decir" a los cuales ellas evitan ingresar, porque desde sus dirigentes y sus propios rebaños reciben mensajes, miradas y discursos violentos. En nombre de "Dios" se les maltrata y humilla. Es una violencia justificada desde lo religioso. La informante \# 5 Alexa, exteriorizó que ella una vez al entrar a una iglesia en Heredia como mujer, el sacerdote de esa misma institución la vio y, posteriormente, fue a acusarla al centro educativo donde trabajaba (en el cual Alexa tenía que presentarse vestida como un hombre) porque se consideró que su identidad de género no era buen ejemplo para las niñas y los niños que recibían clases con ella. En esta ocasión, la comunidad donde ella vivía y los funcionarios del centro educativo la apoyaron y la protegieron, arremetiendo contra las acciones del líder religioso (A. Araya, comunicación personal, 13 de marzo del 2017).

Esta violencia transfóbica es justificada desde lo "legal" en las instituciones públicas. Ellas enfrentan el acoso y la estigmatización permanente en las instituciones educativas donde docentes se niegan a llamarlas por su nombre de mujer; también sufren el acoso, en el campo laboral en general, cuando se les niega el acceso al trabajo por su identidad de género, lo mismo en el sistema de salud cuando las ven como portadoras de enfermedades de transmisión sexual o cuando son excluidas, ignoradas o agredidas por los sistemas jurídicos y legales. 
En términos generales, según Gallardo (2016), el acoso sexual en los espacios públicos es una forma de violencia jurídica para las cuales el Estado costarricense no tiene herramientas apropiadas para actuar, a pesar de que existen normas e instituciones policiales y judiciales; en muchas ocasiones lo que hacen estos entes es reproducir las diversas formas de violencia sexista que maltrata, de igual manera, a las mujeres agredidas, acosadas y violadas, lo cual hace que desistan de las denuncias y acusaciones.

Ante lo desarrollado hasta aquí, es fundamental reconstruir algunos escenarios y exponer las diversas manifestaciones de acoso sexual que enfrentan las mujeres trans en los espacios públicos como las calles, los espacios socio-recreativos y las instituciones públicas en Costa Rica, todo esto con el fin de acercarnos y mostrar las diversas formas de violencia que viven y que están invisibilizadas.

\section{¡La calle es pública, mi cuerpo no! Diversas manifestaciones de acoso sexual transfóbico}

Para comprender lo anterior, es esencial analizar detalladamente las diversas manifestaciones de este tipo de flagelo. En primera instancia se analizó lo que viven estas mujeres en los espacios socio recreativos y en las calles. Según las mujeres trans con las que se trabajó, el acoso sexual en lo público y lo privado es cotidiano en la vida de ellas, para estas personas el Estado no hace nada, ni tiene compromiso para evitar o erradicar este tipo de violencia. Dos de las informantes sienten que dentro del falogocentrismo sus cuerpos no son tan directamente acosados cuando van acompañadas de un hombre.

La informante Stacy expuso que cuando transita por algunos lugares de su comunidad la acosan cotidianamente, mientras que al ir acompañada por su ex pareja, los hombres no le gritan ni le dicen nada, (S. Mora, comunicación personal, 12 de abril del 2017). En el caso de Samantha dice que al ir acompañada de un hombre siente más protección en las calles, lo que permite entender que el respeto que existe en los espacios públicos masculinizados es solo para los hombres (Salas, 2017).

Esta misma informante manifestó que el flagelo del acoso sexual se comenzó a debatir con mayor fuerza por los medios de comunicación cuando fue denunciado por un hombre llamado Gerardo, quien vía redes sociales y denunció un caso de acoso contra una mujer en pleno centro de San José (Salas 2017); esto quiere decir que cuando son las mismas mujeres quienes lo denuncia estas no son escuchadas y son tratadas con términos peyorativos como "corta penes" o "feminazis". 
Visto así, se puede afirmar que el acoso sexual contra las mujeres adquiere relevancia cuando es un hombre quien lo denuncia, lo que conlleva a la idealización de este hombre, el cual termina siendo reconocido socialmente como un héroe que protege mujeres "indefensas y débiles". Pero también cuando es el hombre la víctima de acoso sexual, los medios de comunicación y la sociedad, en general, lo denuncian como una violencia injustificable cuando no debería ser justificable para ningún ser humano.

Según las pesquisas encontradas, en la mayoría de los casos, los hombres son los principales victimarios que atentan contra la dignidad de estas mujeres; no obstante, las miradas hirientes y despreciativas de otras mujeres cisgénero también son parte del acoso que enfrentan todos los días. Este hombre victimario es un producto de un sistema capitalista patriarcal/colonizador y esa misma actitud victimaria contra las mujeres trans es asumida por la mujer cisgénero y producida también por este sistema.

Para Bourdieu (2000), los hombres y las mujeres han incorporado, de forma inconsciente, esquemas de percepción y de apreciación de las estructuras históricas del orden masculino y es, desde esta lógica, desde donde las mujeres cisgénero ven con desprecio y tratan con discriminación a muchas mujeres trans. Además, la lógica falogocentrista que impone la rivalidad entre las mujeres, hace que, si las mujeres trans son consideradas como "bonitas" por la sociedad, algunas mujeres cisgénero las perciben como competencia.

En el periódico La Nación, una mujer trans opinó que en la actualidad, personas menores de edad las agreden en las calles: Pero, últimamente, ha sido víctima de agresiones por parte de grandes grupos de niños, de entre los 8 y los 14 años: "Si la ven sola a una, se acercan, me rodean y me maltratan toda".

La informante \# 6 Gabriela expresó que en ocasiones siente acoso por parte de las personas menores de edad:

Están desde las más básicas, sencillas y hasta inocentes digamos, cuando un chiquito le dice a la mamá "pero ¿es un chico o una chica?" o "parece un chico, pero es una chica" porque los chiquitos son muy inocentes, ellos no tienen ese morbo ni esa malicia, verdad. Entonces me ha pasado montones de veces que los chiquitos dicen ese "parece un chico, pero es una chica". Y entonces la mamá llega y le susurra algo al oído y los chiquitos se quedan callados (G. Umaña, comunicación personal, 12 de abril del 2017). 
Este testimonio de Gabriela, además de expresar una manifestación de acoso, que ella considera inocente (de las niñas y los niños), demuestra cómo, según el transfeminismo, dentro de las sociedades occidentales lo binario hombre/mujer está incorporado en las personas desde edades tempranas. Este binarismo se cimienta desde los procesos de socialización familiar y educativos, tanto formal como informalmente.

El Estado "democrático" costarricense es responsable de que a la población infantil y adolescente no se les enseñe a entender o comprender la diversidad de género y sexual que compone el tejido social. Hay algunas políticas públicas para respetar la identidad de género, pero se quedan en el papel y no se concretizan en la praxis educativa del sistema formal.

Por su parte, las iglesias promueven marchas de odio y violencia contra estas poblaciones y las generaciones de menores de edad lo entienden como lo moralmente correcto, con lo cual se permean de prejuicios y sexismo. Por lo anterior, al confrontarse grupos infantiles y adolescentes con una mujer trans, lo perciben como algo ajeno, abstracto, no "normal", imposible de comprender, de clasificar $\mathrm{y}$, por ende, una persona objeto de rechazo y desprecio.

Alexa comentó a la investigadora que sus vecinas, unas adolescentes entre los 14 y 16 años pasan burlándose de ella cuando entra y sale de su barrio solo por ser una mujer trans. Esto permite deducir que el acoso sexual transfóbico se ejerce, de forma naturalizada, por parte de diversos grupos etarios de la sociedad costarricense, niñez, adolescencia y adultez son parte de los entes victimarios con los que tienen que enfrentarse las personas trans. Stacy, en una conversación informal, compartió que un niño vecino de ella le preguntó si antes era hombre; ella asumió que la mamá del niño le había hecho el comentario y sintió molestia de ver cómo la gente adulta de su comunidad sigue recordándole a las nuevas generaciones su pasado. También en una ocasión un niño le dijo al sobrino de ella que su tía Stacy era un hombre, su sobrino llegó llorando y Stacy pudo explicarle las circunstancias que ella vivió como ser humano, y el niño pudo entenderle.

Probablemente la misma discriminación que ejerce la gente adulta es reproducida por los grupos de menores que se ven permeados por prejuicios y estereotipos ya cimentados desde décadas atrás por algunas iglesias y los medios de comunicación. Estos estereotipos son reproducidos en el ámbito familiar, escolar y en todos los espacios de educación informal. No obstante, según el testimonio de Natalia, hay excepciones, ella opinó que en muchas ocasiones son las niñas y los niños quienes mayormente las aceptan y las ven con naturalidad: 
Pero vieras que es muy bonito, porque a veces los niños te ven diferente, te dice cosas diferentes, una vez estaba en un restaurante de hamburguesas y había una niña, y me volvió a ver y estaba con su mamá y ella le dijo: -vea, mami, una Barbie-, y yo, entonces yo volví a ver a la chiquita (Porras 2017).

Situaciones como estás donde las niñas y los niños ven con respeto y como iguales a las mujeres dependen mucho de la formación y la socialización que tengan.

Una mujer trans entrevistada por el periódico La Nación expresó que el acoso sexual transfóbico que enfrentan las poblaciones trans "Es como si fuera un pasatiempo de esta gente", refiriéndose a sujetos sociales que las agreden. Este tipo de violencia demuestra que la sociedad patriarcal cosifica a las mujeres trans. Quienes las agreden descargan sus frustraciones personales y canalizan el desprecio y el odio por medio de la mofa y la burla de los cuerpos y las identidades trans. Tratan a estas mujeres como objetos de diversión y carnaval, mientras que la violencia que ejercen los llena de placer y los empodera como "machos" dueños del espacio público. Este tipo de manifestaciones transfóbicas se sustentan en el desconocimiento e inseguridades que tienen las personas "heteronormalizadas" sobre el género y las normas impuestas al respecto.

Para la mayoría de las mujeres entrevistadas, los espacios públicos no son lugares seguros, sienten miedo a ser violadas y agredidas, sujetas a burlas y discriminación:

Ese tipo de violencia que sufren todas las mujeres, el caminar por una calle y andar sola y que aparezca un mae, el miedo porque una camina con miedo de ser violada, no con el miedo de que la asalten, que la asalten es lo de menos (risas) que se lleven todo, que se lleven todo es lo de menos (risas) si quieren, pero que no me vayan a tocar el cuerpo (Rovira 2017).

Para Victoria, las mujeres caminan por las calles con el miedo de ser violadas, este no es un temor solo de las mujeres trans, es un temor imperante también en las mujeres cisgénero. Sin embargo, la violencia de género mezclada con la transfobia hace entendible el doble temor que tienen las mujeres trans de desplazarse con libertad por los espacios públicos, dadas las experiencias desagradables que enfrentan día a día en un espacio heteronormalizado, patriarcal y transfóbico que rechaza todo lo diverso y lo no binario.

Para las mujeres trans las manifestaciones de acoso sexual y "social" (como lo llama Natalia) que ellas enfrentan en los espacios públicos son numerosas, van desde la violencia verbal, gestual y física. Para Natalia las mujeres trans son vistas como amenazas en el espacio público: "Bueno, a veces lo ven a una como 
una amenaza digamos, como, cuando están en grupo es como ver una manada de monos, es como ver un animal que les produce una amenaza" (Porras 2017). Por su parte, la informante \# 7 Lorna exteriorizó que, cuando ella está en las calles, las personas "se le quedan viendo a uno como si uno fuera un monstruo" (L. Umaña, comunicación personal, 2017).

Al contrario de lo que se construyó en el imaginario social costarricense y se difundió por los medios de comunicación sobre las mujeres trans, acusándolas de delincuentes y violentas, la mayoría de las veces son ellas las que están en constante peligro por la transfobia que enfrentan. Existe un pánico social sobre la sexualidad y las identidades trans; para el imaginario colectivo son agresivas, son ladronas, son sidosas y son exhibicionistas.

Como lo expone Hinkelammert (1999), este caso puede entenderse como una inversión de los derechos humanos. Las mujeres trans han sido, históricamente, violentadas: pero desde las percepciones de quienes ejercen el poder patriarcal contra ellas, ellas son culpables de violentar la moral, la heteronormalidad, la masculinidad dominante y la familia tradicional; ante ello es necesario defenderse de estas mujeres por ser consideradas como una amenaza para la sociedad tradicional (patriarcal, cristiana y heternormalizada).

Al "atentar" contra la sociedad tradicional, estas mujeres pierden el carácter de ser humano, pueden ser sometidas y aniquiladas por quienes tienen el poder. Para Hinkelammert, el sujeto poderoso puede hacer con ellas lo que se le antoje en nombre de defender la normalidad y el respeto por los preceptos morales: esto constituye una inversión del mundo donde las víctimas se posicionan como las culpables.

En relación con el acoso sexual transfóbico, algunas mujeres trabajadoras sexuales entrevistadas por el periódico La Nación no logran comprender cuál es la necesidad, de quienes las acosan, de violentarlas: "No entendemos por qué hacen eso; nosotras solo estamos trabajando, no molestamos a nadie". Muchas de ellas no tienen otra opción que prostituirse, ya que es una de las pocas formas de sobrevivir que poseen y que les permite acceder a bienes materiales dentro de un Estado y una sociedad que violenta el derecho a su trabajo (principalmente en el área pública) por su identidad de género. 


\section{¡Mi cuerpo no quiere tu opinión! El acoso sexual verbal y gestual contra las mujeres trans}

Es constante para las mujeres trans enfrentar insultos, obscenidades y humillaciones por parte de las personas que no respetan su identidad de género. La informante Gabriela cuenta que es cotidiano que pasen hombres y le griten: "los maes que pasan en un carro y me gritan, 'diay qué se yo, no sé, estupideces: 'rica' o 'mi amor' o "venga para tal cosa"” (Umaña 2017).

En el caso de Samantha, el acoso sexual que afronta es tal como lo experimenta una mujer cisgénero, porque los rasgos físicos de ella no son para nada masculinos, por lo que casi nadie la identifica como una mujer trans: comentarios, así como "rica, preciosa" (Salas 2017). Lo mismo le sucede a Stacy, quien en pocas ocasiones es reconocida como una mujer trans. Lo anterior, permite argumentar que el acoso sexual se vuelve transfóbico cuando la sociedad identifica los rasgos masculinos de estas mujeres. Cuantos más rasgos cisgénero tengan las mujeres trans son menos propensas a sufrir transfobia y la agresión se "limita" al acoso sexual que vive cualquier mujer.

Según una periodista de La Nación, realizando un trabajo con esta población trans en la calle, fue testigo del acoso sexual transfóbico que padecen estas mujeres; cuando unos hombres pasaron en un carro y les gritaron: "¿A cuánto venden el kilo de huevos?".

La informante \# 8, llamada Wendy, otra de las mujeres entrevistadas, exteriorizó que cuando pasa por un lugar público, al ser ella una mujer trans de edad avanzada, le gritan que está fea: "ya tengo cincuenta y seis años, entonces, uno no puede compararse tal vez a una chiquilla trans o una mujer con buen cuerpo, entonces me dicen 'mire tan fea', así le dicen a uno" (W. Sánchez, comunicación personal 8 de abril del 2017). El testimonio de Wendy permite entender cómo el acoso sexual que ella sufre es el acoso sexual por ser mujer, por ser trans y por ser de edad avanzada, lo que la posiciona en una desventaja social en relación con otras mujeres; la transversalidad de estos factores agudiza el acoso sexual que enfrenta.

Con el testimonio de Wendy, Samantha y Gabriela es obvio que el acoso sexual a las mujeres trans puede ser comparado con el acoso que enfrentan las mujeres cisgénero, pero en algunos casos es indudable el acoso sexual transfóbico como fue el caso que expuso la periodista del periódico La Nación. Además, Samantha comentó que a unas amigas de ellas sí les insultan por ser mujeres trans: "sé que a amigas le han dicho 'travesti', "playo"' (Salas 2017). 
A pesar de los testimonios anteriores, dos de las informantes argumentaron que se sienten bien cuando le dicen "un piropo", ya que se sienten hermosas, femeninas y aceptadas. Para Arias-Cruz (2016), el acoso sexual llamado "piropo" es una forma de acoso que el patriarcado ha naturalizado y que termina por ser aceptado como algo bonito por una gran cantidad de mujeres. Probablemente, algunas mujeres trans acepten determinados piropos como una forma de aceptación social y como muestra, de alguna manera, de que la sociedad no ha descubierto algunos rasgos fenotípicos que todavía mantienen.

Es fundamental cuestionarse, si a estas mujeres trans verdaderamente les agradan los "piropos bonitos", dado que esta forma de violencia se ha normalizado en la vida cotidiana de todas las mujeres, quienes han interiorizado y naturalizado los discursos patriarcales. Para Arias-Cruz, la brevedad de la duración del acoso sexual verbal, así como la manera en que se manifiesta disfrazada de halagos, susurros, expresiones "bonitas" (que lo hacen aparentemente intangible) revela la apropiación masculina del cuerpo femenino y el encubrimiento de la opresión.

Según Arias-Cruz, la naturalización de los "piropos decentes" y los "piropos vulgares" es una forma de dominación masculina naturalizada sobre los cuerpos feminizados. Por medio del acoso sexual en los espacios públicos, es implícito el derecho de dominación que tienen los hombres sobre los cuerpos de las mujeres. Imponen sus deseos patriarcales sin importar, si son aceptados, son degradantes o son molestos para ellas, convirtiendo el acoso sexual en los lugares públicos en una expresión de la violencia de género poco cuestionada.

Mediante al acoso sexual público se interiorizan las imposiciones de género que reproducen los estereotipos de la belleza, belleza determinada por los hombres. Ellos son los que aprueban, mediante comentarios, cuáles son las mujeres socialmente aceptadas. La normalización de este tipo de acoso sexual "sutil" es la aceptación de la dominación masculina del cuerpo y de los espacios públicos, por ende, las mujeres trans que más cumplan con los estereotipos de belleza occidental son más aceptadas y naturalizadas por los hombres y por las mujeres cisgénero.

Para Muñiz (2014), la belleza occidental, impuesta por el capitalismo, destruye los rasgos físicos de lo que es políticamente incorrecto, impone el racismo, mutila la etnicidad no europeizada y se fundamenta en el patriarcado, desprecia lo indígena, los cuerpos voluminosos, lo queer, lo latinoamericano y lo africano, etcétera.

La autora establece que la belleza occidental impone estándares de belleza que aceptan solo los cuerpos delgados, sin grandes curvas, que proyecten debilidad, pero además demanda el cabello rubio, los ojos verdes o azules y el cabello lacio. 
Estos idearios de belleza se van transformando, de acuerdo con las clases sociales y al poder adquisitivo de las personas, y dependen mucho del nivel de occidentalización de los países.

Los dobles esfuerzos realizados por las mujeres trans para asimilar sus rasgos físicos con los de las mujeres cisgénero, en muchas ocasiones ponen en riesgo sus vidas, principalmente porque se someten a procesos de transformación estética de bajos presupuestos y de malas praxis que atentan contra su salud; les inyectan aceites no aptos para agrandar los glúteos y caderas, o se abren las prótesis de silicón para agrandar los senos. Para Samantha, las mujeres trans reproducen estos estándares de bella occidental como forma de sobrevivencia: "hasta cierto punto la feminidad estereotípica es una cosa de supervivencia para nosotras las mujeres trans" (Salas 2017).

En el caso de Stacy, es una mujer que a pesar de que se ha esforzado doblemente por cumplir los estereotipos de la belleza occidental, ha vivido acoso sexual transfóbico en las calles, es algo con lo que tiene que lidiar y, en muchas ocasiones, no quiere ni salir de su casa: "Todos los días, hay que prepararse para recibir lo más sutil que te puedan decir, como "que rica que estás' a lo más grosero, como 'playo', 'loca', 'fea'” (S. Mora, comunicación personal, 15 de marzo del 2017).

La informante Alexa reveló que en ocasiones pasa por las calles y aceras y principalmente le gritan "Ay, qué bonito el maricón" o "Que bonita la..." o le dicen a uno "playo...playo feo' para, para denigrarlo" (Araya 2017). Alexa expuso que las sátiras o el doble sentido es parte del acoso sexual que enfrentan en los espacios públicos como en los comercios; este es un acoso indirecto, pero innegable para estas mujeres: "vienen las sátiras, o viene esa hijueputa... expresión, y perdóneme que utilice esa palabra, pero es que me da cólera cuando me acuerdo, discúlpeme, yo sé que está mal, pero me da mucha cólera cuando te dicen "Ahí te buscan'”. También expresó:

Una vez me pasó eso en una exposición de pintura aquí en la... ahí por el Estadio Nacional ¿Cómo es que se llama ese lugar donde está el Estadio Nacional, que lo donó el Padre ese? Bueno La Sabana. Ahí hicieron una exposición y diay me meto yo a ver, estaba el chavalo hablando con el que estaba pintando, no sé qué por qué fue, y entro yo y dicen "Aquí lo buscan", algo así. (Araya 2017)

Las expresiones como "Ahí te buscan" (o frases similares) son utilizadas por hombres heterosexuales que le dicen a un amigo que esa mujer trans "percibida como un homosexual lo está buscando, es una manera de ridiculizar la masculinidad de su amigo, pero a la vez de violentar a las mujeres trans". 
A través de este tipo de comentarios se desarrollan juegos de poder de los hombres sobre las mujeres, pero también de lo heterosexual sobre lo sexualmente diverso. Estos juegos promueven y demarcan los distintos prejuicios transfóbicos, sexistas que fortalecen y consolidan el acoso sexual y las imposiciones de identidad de género tradicionales sobre las mujeres trans.

En el caso de Gabriela, ella enfrentó, en un centro público, una manifestación clara de la violencia simbólica. Ella expresó que en una ocasión se encontraba con un grupo de amigos y amigas en un bar y que de repente sonó una canción que hacía burla de un "travesti":

La más fea que me pasó fue una vez que andaba en un bar ahí en Cartago, tuanis, tomando, comiendo con las compas y de pronto me ponen una canción creo que era de los Ajen... o una vara así que hablaba sobre una mae que era travesti y que todos iban allá y que todos la amaban, pero era una canción súper transfóbica, verdad. Y claro, yo estaba así como..., empiezo a oír la canción porque escucharla no, verdad, pero empiezo a oír la vara y me hizo gracia, verdad, pero de pronto me puse a ver a la gente de la barra que estaban cagados de risa, y yo a la puta ah la vara era conmigo entonces. (Umaña 2017)

En este caso es indudable que el acoso sexual que enfrentó Gabriela en dicho establecimiento es una forma de violencia verbal por las burlas que recibió. También es una forma de violencia simbólica, puesto que ella logró identificar que el acoso y la transfobia hacia las personas trans se encuentran difundidas y permitidas en las letras de las canciones populares, que sirven de instrumento de poder falogocentrista para ejercer la violencia contra ellas en los espacios recreativos. Además, este tipo de acciones transfóbicas consolidan y reproducen los estereotipos sociales sobre estas mujeres.

Lorna opinó que cuando ella ha estado en los espacios públicos se ha enfrentado a diversas formas de violencia verbal, le han dicho: "playo hijueputa, playo feo. Hágase hombre hijueputa" (Umaña 2017). El cuerpo y la expresión de género de Lorna no se adapta a los roles tradicionales de género, la frase "hágase hombre", pretende anular y aniquilar lo femenino que hay en su persona. Para la sociedad heteronormalizada es necesario que las mujeres trans abandonen su identidad de género, porque están "enfermas y trastornadas psicológicamente", ellas deben asumir nuevamente la masculinidad hegemónica que les fue otorgada al nacer, lo cual es visto como lo "natural y lo normal".

Según Lorna y Alexa, a Lorna le han gritado sidoso: “Alexa: Sidoso" (Araya 2017). Lorna: "Mhm, sidoso también; lo ven a uno como una basura" (Umaña 2017). 
La palabra sidoso tiene una connotación pesada en la sociedad costarricense, es un término despectivo y estigmatizante que ha generado rechazo desde décadas anteriores para quienes tienen condición de VIH y VIH avanzado. Es necesario entender que las personas con VIH y VIH avanzado en Costa Rica están posicionadas en lo más bajo de la escala social. Debido a los estereotipos cimentados sobre las mujeres trans que son trabajadoras sexuales y que, por ello, están en riesgo de padecer enfermedades de transmisión sexual la sociedad las agrede con ese tipo de expresiones.

Como lo expresa Gallardo (1997), esta condición de VIH y VIH en segundo grado se sigue ligando a las personas sexualmente diversas "homosexuales" a lo "no natural" al "mal comportamiento" como la vida promiscua y el consumo de drogas. Ante este panorama, las mujeres trans enfrentan este tipo de expresiones porque son consideradas por la mayoría de las personas como "lo malo", "lo anormal", libertinas y promiscuas; dentro del imaginario social del costarricense común, ellas son potenciales portadoras del VIH. El acoso sexual transfóbico que reciben algunas mujeres trans que son trabajadoras del sexo, es complejo; se les discrimina por ser mujeres, por considerarla hombres homosexuales, por ser trabajadoras sexuales y por imaginar que tienen enfermedades de trasmisión sexual.

Al ser consideradas las mujeres trans por la sociedad costarricense como mujeres libertinas y promiscuas, con prácticas sexuales abiertas, se abre el portillo para que ellas, en el transporte público, vivan circunstancias desagradables. El año 2016, una mujer trans comentó que en medio de su transición perdió su privilegio masculino y sintió por primera vez el acoso sexual que vivían las mujeres. Ella se subió a un taxi, el taxista le comenzó a preguntar sobre su vida, luego él comenzó a tocarse los genitales, le preguntó cuánto cobraba y le propuso que se fueran para algún lado a mantener relaciones sexuales (A. Pérez, comunicación personal, 11 de noviembre del 2016). En el caso de Stacy, dijo que una vez un taxista le expuso sus genitales y le dijo que se la chupara.

Estos testimonios indican que la sociedad, en general, reduce la homosexualidad, lo transgénero y la transexualidad a lo sexual (pene/vagina) biológico; es decir, ver a un transexual o transgénero es ver a alguien que anda deseando tener relaciones sexuales. Este es un reduccionismo propio de los estereotipos construidos sobre la comunidad LGTBI; parecido al reduccionismo de relacionar homosexual-trans-VIH.

Otra forma de acoso sexual en los espacios públicos es la persecución en las calles que enfrentan constantemente las mujeres trans. En medio del Parque Central de San José, la investigadora logró observar a un hombre de aproximadamente 25 años que seguía a dos mujeres trans. Cuando las mujeres se cambiaban de lado, él 
iba detrás de ellas observándoles las piernas e intentando ver bajo sus faldas (ver Anexo \# 1). La situación anterior se parece a lo que contó Stacy, quién enfrentó una situación similar:

Bueno añadiendo una anécdota a la entrevista de acoso, también de acoso callejero. Muchas veces cuando nosotras andamos por las calles hay muchos tipos que se nos pegan a la par, diciéndonos vulgaridades, hasta el punto en que empiezan a decir "vámonos, vámonos, vámonos para el hotel. Una vez, con mi mamá, de la mano de mi mamá, un tipo se me puso a la par y él tal vez pensaba que mi mamá no escuchaba; me decía vulgaridades "vamos, deje a la señora, metámonos a un hotel, busquemos algún lugar para ir a tener sexo rico". Y entonces del mismo susto, no sabía si el tipo era que me iba a asaltar o qué, nos metimos a una tienda a disimular, ya yo le había contado a mi mamá, ya le había puesto sobre aviso, sobre la situación. Y nos metimos a una tienda y duramos unos cuantos minutos y para sorpresa de nosotras, cuando salimos estaba el tipo en la puerta de la tienda, esperando a que yo saliera. Hasta que ya yo le dije a mi mamá, busquemos un policía para quitarme este tipo de encima. Y el tipo entonces ya como que le entró miedo y aceleró el paso y se nos perdió (Mora 2017).

Victoria, al igual que Stacy, ha tenido que enfrentar este tipo de situaciones: "la vez pasada un mae me empezó a seguir por todo Chepe, no encontraba un solo policía, siempre están ahí, pero cuando los ocupas nunca están (risas), ese tipo de violencias sufrimos todas las mujeres" (Rovira 2017).

Dentro de los mitos que sobreviven en el imaginario social costarricense sobre las mujeres trans es que todas son trabajadoras sexuales; como lo expresó Natalia, son percibidas como personas abiertas al sexo, como objetos sexuales para cumplir las fantasías de muchos hombres. Gabriela también compartió la experiencia que tuvo una de sus amigas trans con un cruzrojista:

Sí, una amiga sufrió acoso hace poquito de un cruzrojista que vive como a... bueno que la Cruz Roja está como a cien metros de la casa de ella. El mae tenía varios días de verla y ella lo notaba, verdad; pero ese día el mae como que no se controló y le cayó así como encima, porque dice ella que sintió como que el mae le llegó con esa idea de que como es trans o de que como era un travesti entonces diay era una puta o era una fácil. (Umaña 2017)

El mito de que las "trans todas, son prostitutas", hace que ellas tengan que enfrentar una de las manifestaciones de acoso sexual más violentas en los espacios públicos, donde son reducidas al sexo coital y, por ende, a la cosificación; son vistas todas como prostitutas, dijo Samantha en la entrevista. 
Victoria compartió otro ejemplo que es parte del acoso sexual que también viven las mujeres trans, este se expresa cuando las personas les dicen que son bonitas y no parecen mujeres trans:

A mí cuando las personas se dan cuenta que soy trans lo primero que me dicen son cosas muy violentas por ejemplo a mí me dicen jay es que usted es muy bonita no parece trans! Entonces en sí no es un cumplido, primero ya yo sé que soy bonita, tengo un espejo en la casa (risas), en segundo lugar, se piensa que para ser trans no se puede ser bonita. (Rovira 2017)

Las mujeres trans tienen que hacer un doble esfuerzo para cumplir con los estereotipos de la belleza occidental. Para ello se someten a tratamientos hormonales y cirugías estéticas, en diversas ocasiones ponen en riesgo su vida. Para Stacy, entre más cisgénero puede verse una mujer trans es menos propensa a ser violentada en los espacios públicos:

El afán de muchas de nosotras por someternos a cirugías dolorosas, a procesos hormonales, para cada día asemejarnos más a una mujer cisgénero, para poder evitar cualquier indicio de masculinidad que haya en nuestros cuerpos, para evitar ser discriminada cuando andamos por las calles. (Mora 2017)

En el caso de Victoria, al reafirmarle la sociedad que ella es una mujer hermosa deja percibir que, para el imaginario colectivo de la gente común, las mujeres trans son personas feas y masculinas. Ella considera que ese tipo de comentarios es una clara expresión del acoso sexual que sufren constantemente. Además, dijo que cuando ha caminado en algún momento por las calles y la han identificado como una mujer trans la gente le dice "mira un travesti", Alexa ha enfrentado la misma situación: "mira ahí va un travestí".

Travesti fue la etiqueta impuesta sobre las mujeres trans en la década de 1990 por los medios de comunicación escritos y de la televisión nacional y, que se popularizó en la sociedad costarricense (en la década de 1980 se les denominó como travestidos). Travestí es un término que se utiliza en público para discriminar a las mujeres trans, para hacer burla de ellas o para reafirmar que son "hombres vestidos de mujer".

Otra forma de acoso sexual constante que enfrentan estas mujeres se genera cuando gente conocida les siguen llamando públicamente por su nombre de nacimiento. Después de la entrevista a Samantha, una amiga de ella compartió que, estando una vez con otros amigos en un bar en Heredia, estos amigos llamaron a Samantha por su antiguo nombre y ella se enojó demasiado. Gabriela manifestó lo siguiente: 
Gentecilla que nunca me quiso y que ni de contacto tengo en Facebook... Y se atreven a llamarme por un nombre que nunca me perteneció...Por esas y otras razones es que me ahueva demasiado acercarme a San Carlos... Los envidiosos, los tontos, los apáticos y los intolerantes quedan en el olvido uno a uno, con cada estupidez que dicen. (Umaña, 2017)

Cuando las mujeres trans adoptan un nombre social que les reafirma su identidad de género y que les permite identificarse e imponerse ante las demás personas, deben tratarse en lo público y en lo privado conforme a la expresión de género que ellas quieren. Al igual que Gabriela, Wendy relató que en su barrio algunas personas aún le llaman por su nombre masculino, principalmente los evangélicos que pretenden que ella vuelva hacer un hombre y que, erróneamente, creen que llamándola por su antiguo nombre ella se va a transformar: "a veces me tratan por Javier, alguno que otro me dice Wendy, pero muchos son cristianos, entonces, ellos creen que diciéndome el otro nombre yo me voy a convertir" (Sánchez 2017).

Llamarle a una mujer trans por el nombre impuesto al nacer es una manifestación de violencia y acoso sexual; es una forma de negarles su identidad, lo cual causa daños emocionales en estas personas. Una mujer trans, entrevistada por el diario digital El Periódico $\mathrm{Cr}$, expresó, mediante un video, la situación de llamarles a ellas con el nombre impuesto al nacer; las hace desertar de espacios públicos como los colegios y revertir los logros personales relacionados con su identidad de género: "a muchas de nosotras nos da miedo ir a estudiar porque nos van a llamar con un nombre que no nos sentimos identificadas, entonces nos vamos a sentir que la gente nos va a estar humillando y nos van a estar diciendo el nombre para hacernos sentir mal" (El Periódico Cr, septiembre 2014).

Uno de los peores daños que pueden enfrentar las mujeres trans es que las sigan tratando con el mismo género que fue obligada a vivir en el pasado. Llamarlas por el nombre pretransición es una forma de exclusión y estigmatización que cimienta aún más las desigualdades sociales. Ellas están seguras de que las personas que las llaman por su antiguo nombre tienen poca sensibilidad, sienten que lo hacen para humillarlas y recordarles el pasado que ellas quieren olvidar, es violentar su derecho al olvido.

Lo más difícil de tales acciones transfóbicas es que muchas veces provienen de personas cercanas, como familiares y amigos que han vivido en sus vidas, antes, durante y después de la transición. Esto es una manifestación de cis-sexismo, el cual consiste en que una persona cisgénero sea sexista con otra por su identidad trans. 


\section{¡Soy más de lo que ves! Las miradas, una expresión más del acoso sexual hacia las mujeres trans}

La mayoría de las mujeres entrevistas coincidieron en que las miradas son parte del acoso sexual que enfrentan. Este tipo de hostigamiento es una manifestación clara de violencia psicológica, la cual es un conjunto de comportamientos heterogéneos que, de alguna manera, producen agresión en las personas que la enfrentan; puede ser intencional y justificado, en este caso, desde la transfobia donde el sujeto agresor reconoce hacer daño a la persona observada con rechazo o desprecio. También puede ser no intencionado, pues la sociedad no está educada para la no exclusión y para el respeto de las diversas sexualidades e identidades de género.

Las miradas son un tipo de acoso sexual callejero común, pero es poco reconocido como hostigamiento sexual, mucho menos cuando van dirigidas hacia las personas con identidades de género que se apartan del binarismo. En las vidas de las mujeres trans, este tipo de acoso ejercido por medio de las miradas tiene un fuerte peso emocional. Gabriela expresó que cuando salió a un espacio público la primera vez como una mujer, lo más difícil que enfrentó fueron las miradas:

Yo no sé, al rato era idea mía, pero estaba tan nerviosa que sentí que todo el mundo me estaba viendo y diay por supuesto que las miradas acusadoras y las miradas acosadoras se dieron desde el primer momento, o sea desde que sentí ese acoso, digamos, homosexual, de ver el morbo de los maes viéndote horrible, o sea, no sé, diay, era la primera vez que lo hacía. Tenía como treinta y un años, una cosa así, y diay no estaba preparada para eso, nadie me había contado cómo era eso, porque como yo lo tenía escondido entonces diay me tiré así al agua y fue una impresión demasiado fuerte, fue demasiado traumático. De hecho, creo que esa fue una de las cosas que más influyó en que yo pusiera una pausa a ser Gaby. (Umaña, 2017)

El testimonio de Gabriela deja claro que las miradas que enfrentó tuvieron un peso emocional determinante para postergar su proceso de transición. Las miradas aumentan el miedo de las mujeres trans de enfrentarse tal y cual ellas son ante una sociedad heteropatriarcal. Gabriela, además de enfrentar miradas transfóbicas, tuvo que afrontar las miradas lascivas por parte de hombres. Samantha también dijo sufrir este tipo de miradas lujuriosas: "en la calle, si recibo algo es acoso como las miradas invasivas de los maes" (Salas 2017). Estas miradas lascivas generan incomodidad y repulsión en la mayoría de las mujeres, los hombres observan el cuerpo femenino con morbosidad y con un cierto grado de perversión.

Gabriela define este tipo de acoso sexual de las "miradas" como agujas entrando a su cuerpo, para ella es difícil enfrentarse diariamente a la gente por esta forma 
de violencia. La informante también define esas miradas como feas y curiosas: "sí porque es como cuando vos llegás a alguna tienda o al súper o a un bar o a donde sea y la gente te vuelve a ver feo o te vuelve a ver con curiosidad" (Umaña 2017).

Natalia comparte, que además de ser las mujeres trans observadas como amenazas en los espacios públicos también son despreciadas:

A veces la ven a una con desprecio, creo que las miradas son bastante hirientes, muchas veces y más cuando nosotras somos bastantes perceptivas, entonces a veces sí son incomodas, porque cuando uno no conoce algo prefiere negarlo o rechazarlo, antes que entenderlo, entonces son muy hirientes con la forma de ver tanto hombres como mujeres. (Porras 2017)

Lorna manifestó: "se le quedan viendo a uno como si uno fuera un monstruo". Por su parte Stacy expresó que las personas las miran con rechazo y asco: "Desprecio, repulsión, te miran feo" (Mora 2017). Para un video del medio de comunicación ameliarueda.com, una mujer trans dijo: "En mi caso es cuando hablo, por ejemplo, montarme a un bus y que el bus va lleno y me suena el teléfono, entonces, cuando yo digo ¡Alo! Usted ve cuando todo el mundo se vuelve (a verla), y ya la gente se empieza a codear (Rueda 2013).

Al caminar y frecuentar algunos espacios públicos con algunas mujeres trans la investigadora logró captar que las miradas sobre ellas son algo constante y obvio. Las personas las observan con extrañeza, con asombro, con desprecio, con asco y de manera negativa. El acoso sexual que enfrentan las mujeres trans por medio de las miradas proviene de todas las personas que componen el tejido social, se ejerce desde personas con alta escolaridad hasta la de más baja escolaridad.

En una ocasión, cuando la investigadora caminaba con una de las mujeres trans en la Universidad Nacional, las miradas de asombro se evidenciaron desde estudiantes hasta personal académico formado en ciencias sociales, quienes observaron a la compañera trans con extrañeza. Al desplazarse por las calles de Heredia, centros comerciales o negocios de comida con las informantes, tanto hombres como mujeres las observaban con morbo, con curiosidad y con desprecio; algunas de ellas caminan ignorando la situación, otras con la cabeza agachada para evadir la violencia que se manifiesta directamente sobre ellas. Alexa, por su parte, usa antejos y sombrero para pasar desapercibida (ver Anexo \# 1). Lo anterior permite ver el impacto emocional que generan estas miradas en las mujeres.

El acoso sexual mediante miradas no es considerado acoso sexual, cuando se hace la denuncia, la sociedad ve estas denuncias como algo exagerado que hay que 
dejar pasar. En el caso de las mujeres trans, el imaginario social de la mayoría de la población costarricense justifica que estas mujeres sean observadas de forma violenta, porque son ellas las que se exponen y son las únicas responsables de ser consideradas "raras", por ser "hombres vestidos de mujeres"; cuando las miradas son lascivas reproducen la cosificación de las mujeres, quienes son vistas como objetos sexuales. Ambos tipos de miradas son naturalizadas y legitimadas socialmente, justifican las conductas hetero-patriarcales en los espacios públicos. Lo femenino y lo masculino, desde preceptos modernos hegemónicos, son categorías rígidas e inquebrantables en la mentalidad del ser costarricense.

\section{¡No soy tu chiste! Las burlas, cuchicheos y risas contra las mujeres trans}

Las burlas, los cuchicheos, codazos y risas son parte del acoso sexual transfóbico que enfrentan las mujeres trans en la sociedad costarricense, lo viven constantemente en las calles, lugares de recreación y en el transporte público. La mayoría de las mujeres entrevistadas coinciden que parte del acoso sexual que reciben es por medio de las burlas, cuchicheos y las risas. Así lo compartió Lorna: "a veces uno tiene que andar con la cabeza agachada para no ver los gestos que hacen contra nosotras... bueno siempre se van a burlar en la cara de uno" (Umaña 2017).

Según lo revelado por Natalia, en muchas ocasiones, además de gritarles palabras obscenas, también las abuchean para humillarlas públicamente (Porras 2017). Una mujer trans entrevistada por el periódico Amelia Rueda dijo que en el transporte público la gente se codea al verla y además comienzan a cuestionar, si ella es un hombre o una mujer. La informante Wendy compartió que: "A veces hay personas que yo no sé si se ríen de uno. O sea, tal vez no lo hacen al frente, pero esperan a que pase uno y se burlan, se ríen, y... O le dicen alguna tontera" (Sánchez 2017).

El acoso sexual transfóbico que se ejerce mediante bromas, codazos, cuchicheos y risas puede ser considerado una manifestación de no aceptación, intolerancia, de sexismo y de odio contra las poblaciones trans. Estas acciones son una forma de violencia psicológica, simbólica y moral ejercida desde la moral colectiva. La mayoría de las informantes, y de forma general la mayoría de las mujeres trans, afrontan desde edades tempranas hasta la adultez este tipo de acoso. El acoso sexual transfóbico psicológico tiene como objetivo devastar y destruir la moral de las victimas, estás últimas en ocasiones son incapaces de expresar verbalmente lo que enfrentan, solo tienen sentimientos desagradables que calan en sus vidas. 


\section{Conclusiones}

Los espacios públicos son espacios dominados por el hetero-patriarcado, además, estos son lugares socialmente asignados para el ejercicio de poder de los hombres contra las mujeres cisgénero y trans. En Costa Rica, el acoso sexual es algo que vive la mayoría de las mujeres todos los días, la denuncia de este solo adquiere importancia y se desnaturaliza cuando es denunciado por hombres.

El acoso sexual en los espacios públicos como la calle y las instituciones es una forma de violencia de género que se ejerce de forma predominante en las mujeres sin importar la raza, la etnia, la orientación sexual o los rasgos fenotípicos. Tiene diversas expresiones que incluyen la violencia verbal, expresada mediante gritos (insultos), las palabras vulgares que denigran y ridiculizan, los gestos obscenos, etc. Adquiere un grado de mayor violencia cuando este se manifiesta mediante el abuso físico como acercamientos y tocamientos.

Este hostigamiento sexual que se genera en las calles, lugares públicos e instituciones también se expresan mediante la violencia simbólica (miradas, gestos, cuchicheos, etc.). A pesar de que las mujeres lo sienten y lo definen como algo incómodo, negativo o como una experiencia traumática que impide la libertad de tránsito y que violenta la dignidad, la sociedad lo sigue ocultando y justificando como algo normal, natural, basado en los diferentes prejuicios sexistas que lo fortalecen.

Es fundamental llamar al acoso sexual que viven las mujeres trans como una acoso sexual transfóbico; esto, principalmente, porque se mezcla el acoso sexual con la transfobia, a pesar de que el acoso sexual que las mujeres trans enfrentan en diversas ocasiones tiene manifestaciones parecidas al que enfrentan las mujeres cisgénero, en la mayoría de los casos ese acoso va acompañado de manifestaciones que violentan e irrespetan las identidades de género por lo que lo hace ser un acoso sexual transfóbico.

Según las mujeres trans, el acoso sexual que enfrentan es el mismo que sufren las mujeres cisgénero por ser mujeres, solo que con algunas particularidades que se desprenden por su identidad de género trans. Sin embargo, el acoso sexual sobre las mujeres trans es una expresión más de la transfobia y la misoginia al ser vistas como mujeres, pero también por ser percibidas por el Estado y la sociedad como hombres gays. La renuncia a la masculinidad impuesta al nacer sobre estas mujeres hace que estos seres humanos, en la lógica del patriarcado, se posicionen en escala social más baja por querer ser mujeres (son mujeres) y nacer como hombres 
biológicos. Al renunciar a la masculinidad, hacen que la violencia sea doblemente ejercida por ser percibidas como hombres homosexuales y por ser mujeres.

El acoso sexual transfóbico se ejerce desde diversas escalas de violencia. Por su naturaleza, el acoso sexual es violento para cualquier mujer, pero se torna más violento cuando está mediado por la transfobia. La discriminación y la fuerza con que se ejerce esta violencia dependen de la edad de las mujeres trans; si son mayores las estigmatizan como feas y viejas, las agreden más si son prostitutas, o si no cumplen con los estereotipos de la belleza occidental impuesta desde mucho tiempo atrás. Estas circunstancias hacen que muchas de las mujeres trans tengan que realizar un doble esfuerzo para poder sobresalir y sobrevivir en los espacios limitados por el heteropatriarcado.

El acoso sexual que enfrentan las poblaciones de mujeres trans se sustenta en las reglas sociales de lo "natural" y lo "normalizado, de lo socialmente "correcto", lo normativo, lo que socialmente puede ser rechazable Este acoso sexual es una manifestación de la no aceptación de la ruptura que hacen estas mujeres con la binaridad biológica vagina/pene, mujer/hombre, por el rechazo a la construcción social del género Lo natural, lo binario, lo normal, lo correcto y hasta lo moral dependen de las normas heteropatriarcales mediadas por la moralidad cristiana medieval, normas que las mujeres trans cuestionan y quebrantan.

El acoso sexual en los espacios públicos sobre las mujeres trans es una forma por la cual la sociedad heteronormalizada y falogocéntrica arremete contra lo diverso, contra el cuerpo y las identidades trans. Las violencias que se ejercen contra el cuerpo e identidades no binarias son una forma de expresión del poder patriarcal, que se expresa desde la violencia simbólica, verbal y física, esta última poneo en riesgo la vida de muchas mujeres trans.

El acoso sexual que enfrentan las mujeres trans proviene por parte de diversos sectores sociales donde se involucran desde personas menores de edad; mujeres y hombres de distintos grados de escolaridad, formación académica, credo religioso y clases sociales. No obstante, los principales perpetradores del acoso sexual transfóbico son los hombres, por lo que este acoso está cimentado por la lógica patriarcal; es probable que vean a las mujeres trans como una amenaza, y por eso se expresan violentamente contra ellas, las cuales deben cumplir el rol femenino de "debilidad" y "sumisión".

Los daños emocionales y físicos son irreparables, ellas enfrentan niveles elevados de estrés, miedo, ansiedad y soledad como resultado del acoso y la transfobia. Lo anterior, aunado al cierre de oportunidades en el área laboral y educativa hace que 
muchas de ellas se sumerjan en el consumo de drogas, tengan que prostituirse y piensen en el suicidio como única salida a las dificultades económicas y sociales.

La discriminación expresada mediante el acoso sexual transfóbico que se ejerce sobre las mujeres trans es un mecanismo que funciona como herramienta para el sometimiento y la imposición del poder heteropatriarcal y heteronormativo, con todo lo que implica. Abre la posibilidad de controlar las vidas y los cuerpos de estas personas, con el fin de denigrarlas y estigmatizarlas desde el discurso de lo normal, lo moral y lo natural.

\section{Referencias}

Arias, K. (2016). El acoso callejero y sus implicaciones expresadas a través de la dominación masculina y la violencia simbólica en las mujeres del cantón de Grecia durante el año 2015 [Tesis de grado]. Sede de Occidente, Universidad de Costa Rica.

Berkins, L. (2003). Un itinerario politico del travestismo. http://www.corteidh.or.cr/tablas/ r24187.pdf

Borja, J. (2003). La ciudad conquistada. Alianza Editorial.

Cabrera, M. y Vargas, L. (2014). Transfeminismo, decolonialidad y el asunto del conocimiento: Inflexiones de los feminismos disidentes contemporáneos. http://www.scielo. org.co/pdf/unih/n78/n78a02.pdf

Chaves, K. (2016). ¿Qué sienten al dañarnos? ¿Satisfacción? ¿En serio? http://www.nacion. com/sucesos/crimenes-asaltos/sienten-danarnos-Satisfaccion-serio_0_1569243099.html

Chaves, K. (2016). 14 policías denunciados por abusos de autoridad contra mujeres trans. La Nación. http://www.nacion.com/sucesos/crimenes-asaltos/policias-denunciados-abusos-autoridad_0_1569243100.html

Chaves, K. (2016). Trans lidian con pedradas y balazos cuando ofrecen sexo. La Nación. http://www.nacion.com/sucesos/crimenes-asaltos/Trans-lidian-pedradas-balazos-ofrecen_0_1569243098.html

Chen, P. (2017). Victoria Rovira: Se vive con más violencia siendo mujer trans que cis. La Séptima Entrevista. http://laseptimaentrevista.com/ victoria-rovira-se-vive-con-mas-violencia-siendo-mujer-trans-que-cis

Chichilla, A. (2016). El largo camino hacia la igualdad de derechos LGBTI en Costa Rica. La Nación. http://www.nacion.com/ocio/revista-dominical/largo-camino-igualdad-derechos_0_1569243082.html 
Cordo, J. y Corneli, B. (2006). El cuerpo travesti. Expresión de la lucha por la diversidad. EDULP.

CrHoy. (2015). Transexuales salen adelante pese adversidades https://www.youtube.com/ watch? $\mathrm{v}=$ BvlidBPIRwU\&t $=3 \mathrm{~s}$

Curriel, O. (2014). Descolonizando el feminismo: Una perspectiva desde América Latina y el Caribe. http://feministas.org/IMG/pdf/Ochy_Curiel.pdf

De Sousa, B. (2010). Descolonizar el saber. http://www.boaventuradesousasantos.pt/media/ Descolonizar $\% 20$ el $\% 20$ saber_final $\% 20-\% 20 \mathrm{C} \% \mathrm{C} 3 \%$ B3pia.pdf

Delgado, C. (2006). Análisis del testimonio como fuente oral: género y memoria. https:// halshs.archives-ouvertes.fr/halshs-00104016/document

Díaz, N. (2016). Personas trans: En el cuerpo de otro, en la piel de uno mismo. La Nación. http://www.nacion.com/ocio/revista-dominical/Personas-trans-cuerpo-piel-mismo_0_1569243085.html

Gallardo, H, (2008). El alcance politico de las diversas concepciones de derechosh. http:// heliogallardo-americalatina.info/index.php?option $=$ com_content\&view $=$ article $\&$ i$\mathrm{d}=103 \&$ catid $=11$ : conversaciones $\&$ Itemid $=106$

Gallardo, H. (1996). Elementos de investigación académica. EUNED.

Gallardo, H. (1997). Sida y castigo. Semanario Universidad.

Gallardo, H. (2007). Sobre fundamento de los derechos humanos. http://www.inif.ucr. ac.cr/recursos/docs/Revista $\% 20$ de $\% 20$ Filosof\%C3\%ADa $\% 20 U C R / V o 1 \% 20 X L V /$ Numero $\% 20115-116 /$ Sobre $\% 20$ el $\% 20$ fundamento $\% 20$ de $\% 201$ os $\% 20$ derechos $\% 20$ humanos.pdf

Gallardo, H. Retana, C. (2016). Sexualidades Humanas: el abrazo diverso. San José: Arlekin.

Gallardo, H. y Retana, C. (2016). La producción social del espacio público. El acoso contra las mujeres. Antanaclasis.

Gándara, M. (2013). Hacia un pensamiento crítico en derechos humanos: Aportes en diálogo con la teoría de Joaquín Herrera Flores. https://rio.upo.es/xmlui/bitstream/ handle/10433/628/manuel_gandara_tesis.pdf?sequence=1\&isAllowed=y

Gándara, M. (2014) Repensando los derechos humanos desde las luchas. http://revistaeletronicardfd.unibrasil.com.br/index.php/rdfd/article/viewFile/488/379 
García, E. (2015). Planteamiento sobre una alternativa del sistema interamericano de derechos humanos. Aporrea.

Gaytán, P. (2007). El acoso sexual en lugares públicos: Un estudio desde la Grounded Theory, Redalyc.

Gaytán, P. (2009). Del piropo al desencanto: Los significados de la interacción en el acoso sexual en lugares públicos. Redalyc.

Herrera, J. (2005). La complejidad de los derechos humanos, bases teóricos para una definición crítica. http://www.ceapedi.com.ar/imagenes/biblioteca/libros/338.pdf.

Hinkelammert, F. (1999). Inversión de los derechos humanos: El caso de Locke. http:// educacion.uncuyo.edu.ar/upload/la-inversion-de-los-derechos-humanos-f-hinkelammert.pdf

Magendzo, A. (2002). Pedagogía crítica y educación en derechos humanos. http://www. redacademica.edu.co/archivos/redacademica/proyectos/ddhh/autoformacion_ddhh/ unidad7/anexo_7-11_pedagogia-critica-yeducacion-en-derechos-hvagosto-02.pdf

Márquez, J. (2017). Mujer trans es asesinada y OIJ no reconoce su identidad de género. Diverso Magazine. http://www.mdiverso.com/2017/09/08/ mujer-trans-es-asesinada-y-el-oij-no-reconoce-su-identidad-de-genero/

Mena, F. (2015). Estudiante "trans" exige que le llamen por el nombre que escogió, no con el que se registró. CrHoy. http://www.crhoy.com/archivo/estudiantetrans-exige-que-le-llamen-por-el-nombre-que-escogio-no-con-el-que-se-registro/ nacionales/

Mirabal, A. (2008). Pedagogía crítica: Algunos componentes teórico-metodológicos: Contribuciones para la pedagogía. CLACSO.

Pérez, D. (2015). Muertes de población trans quedan en el olvido y la impunidad. La Prensa Libre. http://www.laprensalibre.cr/Noticias/detalle/48096/454/ muertes-de-poblacion-trans-quedan-en-el-olvido-y-la-impunidad.

Red Lactrans. (2015). Violaciones a los derechos humanos de mujeres trans en Costa Rica, El Salvador, Guatemala, Honduras y Panamá. http://redlactrans.org.ar/site/wp-content/ uploads/2016/01/Informe-COMPLETO.pdf

Reguant, D. (2014). Explicación abreviada del patriarcado. Patagonia Libertaria

Rico, N. (1996). Violencia de género un problema de derechos humanos. CEPAL. 
Rueda, A. (11 enero 2013). Ser una mujer transgénero en Costa Rica. [Video] YouTube https://www.youtube.com/watch? $\mathrm{v}=\mathrm{nO} 6 \mathrm{nXZb84cg \& t=20 \textrm {s }}$

Sánchez, A. (2016). Estreno CRFIC: Con 'Abrázame como antes' la noche sonrió para cuatro divas. La Nación. http://www.nacion.com/ocio/cine/Estreno-CRFIC-Abrazame-sonrio-divas_0_1603039715.html

Schifter, J. (1998). De ranas a princesas, sufridas, atrevidas y travestidas. ILPES.

Solís, A. (2016). El largo camino hacia la igualdad de derechos LGBTI en Costa Rica. La Nación. http://www.nacion.com/ocio/revista-dominical/largo-camino-igualdad-derechos_0_1569243082.html

Ulises, I. (2010). La transfobia en América Latina y el Caribe. Un estudio en el marco de la Red lactrans. Red Lactrans.

Valencia, T. (2014). Teoría transfeminista para el análisis de la violencia machista y la reconstrucción no-violenta del tejido social en el México contemporáneo. http://www. scielo.org.co/pdf/unih/n78/n78a04.pdf 